\title{
Response of Functionally Graded Material Plate under Thermomechanical Load Subjected to Various Boundary Conditions
}

\author{
Manish Bhandari ${ }^{1}$ and Kamlesh Purohit ${ }^{2}$ \\ ${ }^{1}$ Jodhpur Institute of Engineering and Technology, Jodhpur, Rajasthan, India \\ ${ }^{2}$ Jai Narain Vyas University, Jodhpur, Rajasthan, India \\ Correspondence should be addressed to Manish Bhandari; manish.bhandari@jietjodhpur.com
}

Received 8 October 2014; Revised 27 December 2014; Accepted 7 January 2015

Academic Editor: Massimo Pellizzari

Copyright (C) 2015 M. Bhandari and K. Purohit. This is an open access article distributed under the Creative Commons Attribution License, which permits unrestricted use, distribution, and reproduction in any medium, provided the original work is properly cited.

\begin{abstract}
Functionally graded materials (FGMs) are one of the advanced materials capable of withstanding the high temperature environments. The FGMs consist of the continuously varying composition of two different materials. One is an engineering ceramic to resist the thermal loading from the high-temperature environment, and the other is a light metal to maintain the structural rigidity. In the present study, the properties of the FGM plate are assumed to vary along the thickness direction according to the power law distribution, sigmoid distribution, and exponential distribution. The fundamental equations are obtained using the first order shear deformation theory and the finite element formulation is done using minimum potential energy approach. The numerical results are obtained for different distributions of FGM, volume fractions, and boundary conditions. The FGM plate is subjected to thermal environment and transverse UDL under thermal environment and the response is analysed. Numerical results are provided in nondimensional form.
\end{abstract}

\section{Introduction}

Composite materials are widely in use due to their intrinsic mechanical property such as high strength, modulus of elasticity, and lower specific gravity. Further, as a result of intensive studies into metallurgical aspects of material and better understanding of structural property, it has become possible to develop new composite materials with improved physical and mechanical properties. The functionally graded material (FGM) is one such material whose property can be useful to accomplish the specific demands in various engineering applications to achieve the advantage of the properties of individual material. This is possible due to the material composition of the FGM which changes according to a law in a preferred direction. The thermomechanical analysis of FGM structures is one dimension which has attracted the attention of many researchers in the past few years. The applications of FGMs include design of aerospace structures, heat engine components, and nuclear power plants.
A large number of research papers have been published to evaluate the behaviour of FGM using both experimental and numerical techniques which include both linearity and nonlinearity in various areas. A few of published literatures highlight the importance of the present work. The FGM can be produced by gradually and continuously varying the constituents of multiphase materials in a predetermined profile. Most researchers use the power law function (PFGM), sigmoid function (S-FGM), or exponential function (E-FGM) to describe the effective material properties. Delale and Erdogan [1] indicated that the effect of Poisson's ratio on the deformation is much less as compared to that of Young's modulus. Praveen and Reddy [2] examined the thermoelastostatic response of simply supported square FG plates subjected to pressure loading and thickness varying temperature fields. They used the first order shear deformation plate theory (FSDT) to develop the governing equations. They reported that the basic response of the plates which corresponds to properties intermediate to those of the metal 
and the ceramic does not necessarily lie in between those of the ceramic and metal. Reddy [3] found that the nondimensional deflection reached a minimum value at a particular volume fraction index. They used the power law function to calculate the material gradient. Cheng and Batra [4] computed deformations due to thermal and mechanical loads applied to the top and bottom surfaces of the rigidly clamped elliptic FG plate separately. It was found that the throughthickness distributions of the in-plane displacements and transverse shear stresses in a functionally graded plate do not agree with those assumed in classical and shear deformation plate theories. Reddy and Zhen [5] solved the problem using a higher order shear and normal deformable plate theory (HONSDPT) since, in the HOSNDPT, the transverse normal and shear stresses are computed from equation of the plate theory rather than by integrating the balance of linear momentum with respect to the thickness coordinate. It was reported that the assumption of constant deflection is not true for thermal load but it was found to be true for mechanical load. Qian and Batra [6] found that the centroidal deflection for a clamped plate is nearly one-third of that for simply supported plate, and the maximum magnitude of the axial stress induced at the centroid of the top surface is nearly $40 \%$ larger than that for a simply supported plate. Dai et al. [7] analyzed the plate under the mechanical loading as well as thermal gradient and found that the relations between the deflection and the volume fraction exponent are quite different under the two loadings. Ferreira et al. [8] used collocation method third order shear order deformation theory and presented the effect of aspect ratio of the plate and the volume fraction of the constituents on the transverse deflection. Chi and Chung $[9,10]$ studied the effect of loading conditions on the mechanical behaviour of a simply supported rectangular FGM plate. They assumed that Young's moduli vary continuously throughout the thickness direction according to the volume fraction of constituents defined by sigmoid function. The maximum tensile stress of the FGM plate was found to be at the bottom surface of the plate. Wang and Qin [11] concluded that the appropriate graded parameter can lead to low stress concentration and little change in the distribution of stress fields. They assumed that the thermoelastic constants and the temperature vary exponentially through the thickness. Mahdavian [12] obtained the equilibrium and stability equations based on the classical plate theory (CPT) and Fourier series expansion. They found that the critical buckling coefficients for FGM plates are considerably higher than isotropic plates. Ashraf and Daoud [13] derived the equilibrium and stability equations using sinusoidal shear deformation plate theory (SPT). It was concluded that the critical buckling temperature differences of functionally graded plates are generally lower than the corresponding ones for homogeneous ceramic plates. Alieldin et al. [14] proposed three approaches to determine the property details of an FG plate equivalent to the original laminated composite plate. They developed the equations of motion based on the combination of the first order plate theory and the Von Karman strains. Kyung-Su and Ji-Hwan [15] compared numerical results for three types of materials. It was found that the minimum compressive stress ratio is observed for the fully FGM plate with largest volume fraction index. Suresh et al. [16] studied the effect of shear deformation and nonlinearity response of functionally graded material plate and concluded that the effect of nonlinearity in functionally graded composite plates is more predominant in decreasing the deflections in thin plates for side to thickness ratio of 10. Mohammad and Singh [17] obtained the numerical results for different thickness ratios, aspect ratios, volume fraction index, and temperature rise with different loading and boundary conditions. They employed the boundary conditions; for example, all edges are simply supported (SSSS), all edges are clamped (CCCC), two edges are simply supported and two are clamped (SCSC), two edges are clamped and two are free (CFCF), all edges are hinged $(\mathrm{HHHH})$, and two edges are clamped and two are hinged $(\mathrm{CHCH})$. It was noticed that the maximum centre deflection was found for simply supported boundary conditions and least central deflection was found for clamped (CCCC) boundary conditions. Nguyen-Xuan et al. [18] applied the method for static, free vibration and mechanical/thermal buckling problems of functionally graded material (FGM) plates. They analysed the behaviour of FGM plates under mechanical and thermal loads numerically in detail through a list of benchmark problems. Alshorbagy et al. [19] concluded that FG plates provide a high ability to withstand thermal stresses, which reflects its ability to operate at elevated temperatures. Bhandari and Purohit [20] presented the response of FG plates under mechanical load for various boundary conditions, for example, SSSS, CCCC, SCSC, CFCF, CCSS, SSFF, SSSC, SSSF, and SSCF. The power law, sigmoid law, and exponential law were used for the calculations of the properties through the thickness. They also compared the behaviour of isotropic plates (ceramic and metal) with that of the FGM plates. It was concluded that the isotropic ceramic plate has the lowest tensile stress for all the boundary conditions. It was also reported that the maximum tensile stress occurs for CCFF boundary condition and the minimum tensile stress was observed for SCSC boundary condition. Bhandari and Purohit [21] presented the response of FG plates under mechanical load for varying aspect ratios. The power law, sigmoid law, and exponential law were used for the calculations of the properties through the thickness. They also compared the behaviour of isotropic plates (ceramic and metal) with that of the FGM plates.

With the increasing applications of functionally graded materials, it is vital to understand the behaviour of thermomechanical response of FG plates under various boundary conditions. It is also important to study the response of the FG materials following various material gradient laws, for example, power law function, sigmoid function, and exponential function for properties. In both power law and exponential functions, the stress concentrations appear in one of the interfaces in which the material is continuous but is rapidly changing. In sigmoid FGM, which is composed of two power law functions, there is a gradual change in volume fraction as compared to power law and exponential function. Power law function has been applied to many of the FGMs' but application of sigmoid function is sparse in literature. Power law function, sigmoid function, and 
exponential function have been used in various research works separately but the comparisons of the three FGM laws for various volume fraction exponents, ceramic and metal, have been sparse. In most of the research works, FGM plates with edges simply supported and clamped have been considered. Plate subjected to other boundary conditions, for example, clamped, free, hinged, and combined, is also useful but they have been rarely reported. Thermomechanical loaded FGM structures have been researched but thermally loaded plates have been rarely reported.

Keeping this in consideration, the objective of the present work is to examine the thermomechanical behaviour for various boundary conditions, various material gradient laws, and various volume fraction exponents. The results are presented in the form of nondimensional parameters. The comparison of isotropic ceramic, metal, and FGM plates is also presented.

\section{Material Gradient of FGM Plate}

The material properties in the thickness direction of the FGM plates vary with power law functions (P-FGM), exponential functions (E-FGM), or sigmoid functions (S-FGM). A mixture of the two materials composes the through-thickness characteristics. The FGM plate of thickness " $h$ " is modeled usually with one side of the material being ceramic and the other side being metal as shown in Figure 1.

2.1. Power Law Distribution. Material properties of P-FGM are dependent on the volume fraction $\left(V_{f}\right)$ which obeys power law as defined in

$$
V_{f}=\left(\frac{z}{h}+\frac{1}{2}\right)^{n}
$$

where $n$ is a parameter that dictates the material variation profile through the thickness known as the volume fraction exponent, $h$ is thickness of plate, and $z$ is depth measured from the neutral axis of the plate.

The material properties of a P-FGM can be determined by the rule of mixture as given in

$$
P(z)=\left(P_{t}-P_{b}\right) V_{f}+P_{b}
$$

where $P(z)$ is generic material property, for example, elastic modulus, at a particular depth $z, P_{t}$ and $P_{b}$ are generic properties at top and bottom surface of the plate, and $n=$ 0 and $\infty$ denotes fully ceramic plate and fully metal plate, respectively.

Consequently, at bottom surface, $(z / h)=-1 / 2$ and $V_{f}=$ 0; hence, $P(z)=P_{b}$ and, at top surface, $(z / h)=1 / 2$ and so $V_{f}=1$; hence, $P(z)=P_{t}$.

2.2. Sigmoid Law Distribution. Material properties vary continuously throughout the thickness direction according to the volume fraction of constituents defined by sigmoid function [8]. The volume fraction is calculated using two power law

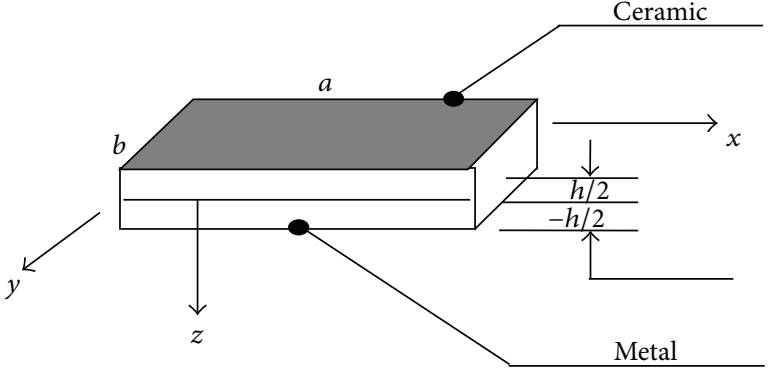

FIGURE 1: FGM plate.

functions to ensure smooth distribution of stresses among all the interfaces. The two power law functions are defined by

$$
\begin{gathered}
g_{1}(z)=1-\frac{1}{2}\left(\frac{h / 2-z}{h / 2}\right)^{p} \quad \text { for } 0 \leq z \leq \frac{h}{2}, \\
g_{2}(z)=\frac{1}{2}\left(\frac{h / 2+z}{h / 2}\right)^{p} \quad \text { for }-\frac{h}{2} \leq z \leq 0 .
\end{gathered}
$$

By using the rule of mixture, Young's modulus of the SFGM can be calculated by

$$
\begin{aligned}
& E(z)=E_{1} g_{1}(z)+\left[1-g_{1}(z)\right] E_{2} \quad \text { for } 0 \leq z \leq \frac{h}{2}, \\
& E(z)=E_{1} g_{2}(z)+\left[1-g_{2}(z)\right] E_{2} \quad \text { for }-\frac{h}{2} \leq z \leq 0,
\end{aligned}
$$

where $E_{1}$ is Young's modulus at the top surface and $E_{2}$ is Young's modulus at the bottom surface.

2.3. Exponential Law. Material properties vary continuously throughout the thickness direction according to the volume fraction of constituents defined exponentially through the thickness. Accordingly, the exponential law is defined as

$$
E(z)=E_{2} e^{(1 / h) \ln \left(E_{1} / E_{2}\right)(z+h / 2)},
$$

where $E_{1}$ is Young's modulus at the top surface and $E_{2}$ is Young's modulus at the bottom surface.

\section{Governing Equations}

3.1. Displacement and Strain Field. The FSDT theory [3] takes into account transverse shear strain in the formulation with the following assumptions.

(1) The transverse normals remain straight after deformation but may not be orthogonal to the midsurface of the plate.

(2) The out-of-plane normal stress $\sigma_{z}=0$.

(3) The layers of the composite plate are perfectly bonded.

(4) The material of each layer is linear elastic and isotropic. 
Under the same assumptions and restrictions, the first order plate theory is based on the displacement field which can be expressed in the following form:

$$
\begin{aligned}
& u(x, y, z)=u_{0}(x, y)+z \Phi_{x}(x, y), \\
& v(x, y, z)=v_{0}(x, y)+z \Phi y(x, y), \\
& w(x, y, z)=w_{0}(x, y),
\end{aligned}
$$

where $\left(u_{0}, v_{0}, w_{0}, \Phi x, \Phi y\right)$ are unknown functions to be determined.

The Von Karman nonlinear strains associated with the displacement field are $\left(\varepsilon_{z z}=0\right)$ given by

$$
\begin{aligned}
& {\left[\begin{array}{c}
\varepsilon_{x x}(x, y, z) \\
\varepsilon_{y y}(x, y, z) \\
\gamma_{y z}(x, y, z) \\
\gamma_{x z}(x, y, z) \\
\gamma_{x y}(x, y, z)
\end{array}\right]=\left[\begin{array}{c}
\varepsilon_{x x}^{0}(x, y, z) \\
\varepsilon_{y y}^{0}(x, y, z) \\
\gamma_{y z}^{0}(x, y, z) \\
\gamma_{x z}^{0}(x, y, z) \\
\gamma_{x y}^{0}(x, y, z)
\end{array}\right]+z\left[\begin{array}{c}
\varepsilon_{x x}^{1}(x, y, z) \\
\varepsilon_{y y}^{1}(x, y, z) \\
0 \\
0 \\
\gamma_{x y}^{1}(x, y, z)
\end{array}\right]} \\
& {\left[\begin{array}{c}
\frac{\partial u_{0}}{\partial x}+\frac{1}{2}\left(\frac{\partial w_{0}}{\partial x}\right)^{2} \\
\frac{\partial u_{0}}{\partial x}+\frac{1}{2}\left(\frac{\partial w_{0}}{\partial y}\right)^{2} \\
\frac{\partial w_{0}}{\partial y}+\phi_{y} \\
\frac{\partial w_{0}}{\partial x}+\phi_{x} \\
\frac{\partial u_{0}}{\partial y}+\frac{\partial v_{0}}{\partial x}+\frac{\partial w_{0}}{\partial x} \frac{\partial w_{0}}{\partial x}
\end{array}\right]} \\
& +z\left[\begin{array}{c}
\frac{\partial \phi_{x}}{\partial x} \\
\frac{\partial \phi_{y}}{\partial y} \\
0 \\
0 \\
\frac{\partial \phi_{x}}{\partial y}+\frac{\partial \phi_{y}}{\partial x}
\end{array}\right]
\end{aligned}
$$

$\varepsilon_{i j}$ are the total strain components. The total strain components are the sum of the elastic strains $\varepsilon_{i j m}$ (due to the applied mechanical loads) and thermal strains $\varepsilon_{T i}$ (due to temperature change). So the total strains are given by

$$
\varepsilon_{i j}=\varepsilon_{i j m}+\varepsilon_{T i}
$$

The total strain components can be divided into tensile strain $\left(\varepsilon_{x x}\right)$ and shear strain $\left(\varepsilon_{x y}\right)$ components given by

$$
\begin{aligned}
& {\left[\begin{array}{l}
\varepsilon_{y y}(x, y, z) \\
\gamma_{x y}(x, y, z)
\end{array}\right]=\left[\begin{array}{llllll}
1 & 0 & 0 & z & 0 & 0 \\
0 & 1 & 0 & 0 & z & 0 \\
0 & 0 & 1 & 0 & 0 & z
\end{array}\right]} \\
& {\left[\begin{array}{c}
u_{0, x}(x, y) \\
v_{0, x}(x, y) \\
u_{0, x}(x, y)+v_{0, x}(x, y) \\
\phi_{0, x}(x, y) \\
\phi_{0, y}(x, y) \\
\phi_{0, x}(x, y)+\phi_{0, y}(x, y)
\end{array}\right]} \\
& \text { Or }\left\{\varepsilon_{b}\right\}=\left[Z_{s}\right]\left\{\varepsilon_{b}^{0}\right\} \\
& {\left[\begin{array}{l}
\gamma_{x z}(x, y, z) \\
\gamma_{y z}(x, y, z)
\end{array}\right]=\left[\begin{array}{ll}
1 & 0 \\
0 & 1
\end{array}\right]\left[\begin{array}{l}
w_{0, x}(x, y)+\phi_{x}(x, y) \\
w_{0, y}(x, y)+\phi_{y}(x, y)
\end{array}\right]} \\
& \text { Or }\left\{\varepsilon_{s}\right\}=\left[Z_{s}\right]\left\{\varepsilon_{s}^{0}\right\} \text {, }
\end{aligned}
$$

where $\left\{\varepsilon_{b}^{0}\right\}$ and $\left\{\varepsilon_{s}^{0}\right\}$ are the nodal bending strains and the nodal shear strains, respectively.

3.2. Minimum Total Potential Energy Formulation. For all the conditions of equilibrium, the potential energy is minimal. The minimum total potential energy formulation is a common approach in generating finite element models in solid mechanics. External loads applied to a body will cause the body to deform. During the deformation, the work done by the external forces is stored in the material in the form of elastic energy, called strain energy. The governing equations for the plate equilibrium are derived based on the principle of minimum total potential energy. So, the total potential energy takes the form as in

$$
\begin{aligned}
\Pi= & \left(0.5 \int_{A}\left\{\varepsilon_{b}^{0}\right\}^{T}\left[D E_{b}\right]\left\{\varepsilon_{b}^{0}\right\} d A-\int_{A}\left\{\varepsilon_{b}^{0}\right\}^{T}\left[D T_{b}\right] d A\right) \\
& +\left(0.5 \int_{A}\left\{\varepsilon_{s}^{0}\right\}^{T}\left[D E_{s}\right]\left\{\varepsilon_{s}^{0}\right\} d A-\int_{A}\left\{\varepsilon_{s}^{0}\right\}^{T}\left[D T_{s}\right] d A\right) \\
& -\sum\{P\}\left\{u^{o}\right\},
\end{aligned}
$$

where $\left[D T_{b}\right]$ and $\left[D T_{s}\right]$ are given by

$$
\begin{aligned}
& {\left[D T_{b}\right]=\int_{z}\left\{Z_{b}\right\}^{T}\left[D_{b}\right] \varepsilon_{T b} d z,} \\
& {\left[D T_{s}\right]=\int_{z}\left\{Z_{s}\right\}^{T}\left[D_{s}\right] \varepsilon_{T s} d z}
\end{aligned}
$$

where $\left\{\varepsilon_{T b}\right\}=\left[\begin{array}{c}\alpha(z) \delta T(z) \\ \alpha(z) \delta T(z) \\ 0\end{array}\right],\left\{\varepsilon_{T s}\right\}=\left[\begin{array}{l}0 \\ 0\end{array}\right], \alpha(z)$ is the thermal coefficient of expansion, and $\delta T(z)$ is the continuum temperature change through the plate thickness. Based on the 
principal of the equivalent single-layer theories, a heterogeneous plate is treated as a statically equivalent, single layer having a complex constitutive behaviour, reducing the $3 \mathrm{D}$ continuum problem to $2 \mathrm{D}$ problem. The equivalent layer of the FG plate can be obtained by integrating the plate material properties through the plate thickness as in

$$
\begin{aligned}
& {\left[D E_{b}\right]=\int_{-h / 2}^{h / 2}\left\{Z_{b}\right\}^{T}\left[D_{b}\right]^{T}\left\{Z_{b}\right\} d z,} \\
& {\left[D E_{s}\right]=\int_{-h / 2}^{h / 2}\left\{Z_{s}\right\}^{T}\left[D_{s}\right]^{T}\left\{Z_{s}\right\} d z,}
\end{aligned}
$$

where $\left[D_{b}\right]$ and $\left[D_{s}\right]$ are the bending and shear material matrices, respectively. These material matrices provide the stress-strain relations for FG plates as in

$$
\begin{aligned}
& {\left[D_{b}\right]=\left[\begin{array}{lll}
\overline{Q_{11}} & \overline{Q_{12}} & \overline{Q_{16}} \\
\overline{Q_{12}} & \overline{Q_{22}} & \overline{Q_{26}} \\
\overline{Q_{16}} & \overline{Q_{26}} & \overline{Q_{66}}
\end{array}\right],} \\
& {\left[D_{s}\right]=\left[\begin{array}{ll}
\overline{Q_{44}} & \overline{Q_{45}} \\
\overline{Q_{45}} & \overline{Q_{55}}
\end{array}\right] .}
\end{aligned}
$$

The $\overline{Q_{i j}}(z)$ are the equivalent material property types of stiffness as a function of the plate thickness direction $(z)$ which follows the power law function (2), sigmoid function ((3a) and (3b)), and exponential function (5). The equivalent material types of stiffness of isotropic FG plate are as in

$$
\begin{gathered}
\overline{Q_{11}}(z)=\overline{Q_{22}}(z)=\frac{E(z)}{1-v^{2}}, \\
\overline{Q_{12}}(z)=v \overline{Q_{11}}(z), \\
\overline{Q_{66}}(z)=\frac{1-v \overline{Q_{11}}}{2}(z), \\
\overline{Q_{44}}(z)=\overline{Q_{55}}(z)=k \frac{1-v}{2} \overline{Q_{11}}(z), \\
\overline{Q_{16}}(z)=\overline{Q_{26}}(z)=\overline{Q_{45}}(z)=0,
\end{gathered}
$$

where $Q(z)$ is the effective young's modulus, $k(=5 / 6)$ is shear correction factor, and $v$ is the effective Poisson's ratio of the material through the plate thickness.

3.3. Finite Element Model. The displacements and normal rotations at any point into a finite element " $e$ " may be expressed, in terms of the $n$ nodes of the element, as in

$$
\left[\begin{array}{c}
u_{0}(x, y) \\
v_{0}(x, y) \\
w_{0}(x, y) \\
\phi_{x}(x, y) \\
\phi_{y}(x, y)
\end{array}\right]=\sum_{i=1}^{n}\left[\begin{array}{cccccc}
\varphi_{i}^{e} & 0 & 0 & 0 & 0 & 0 \\
0 & \varphi_{i}^{e} & 0 & 0 & 0 & 0 \\
0 & 0 & \varphi_{i}^{e} & 0 & 0 & 0 \\
0 & 0 & 0 & \varphi_{i}^{e} & 0 & 0 \\
0 & 0 & 0 & 0 & 0 & \varphi_{i}^{e}
\end{array}\right]\left[\begin{array}{c}
u_{j} \\
v_{j} \\
w_{j} \\
s_{j 1} \\
s_{j 2}
\end{array}\right]
$$

where $\varphi_{i}^{e}$ is the Lagrange interpolation function at node $i$.

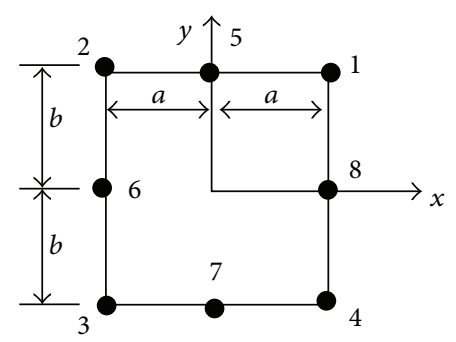

FIGURE 2: Eight-node quadratic Lagrange element.

The Lagrange interpolation functions for eight-node rectangular element (Figure 2) are given by (19) in terms of the natural coordinates:

$$
\left\{L_{e}\right\}=\left[\begin{array}{c}
\varphi_{1} \\
\varphi_{2} \\
\varphi_{3} \\
\varphi_{4} \\
\varphi_{5} \\
\varphi_{6} \\
\varphi_{7} \\
\varphi_{8}
\end{array}\right]=\frac{1}{4}\left[\begin{array}{c}
(1-\xi)(1-\eta)(-\xi-\eta-1) \\
(1+\xi)(1-\eta)(\xi-\eta-1) \\
(1+\xi)(1+\eta)(\xi+\eta-1) \\
(1-\xi)(1+\eta)(-\xi+\eta-1) \\
2\left(1-\xi^{2}\right)(1-\eta) \\
2(1+\xi)\left(1-\eta^{2}\right) \\
2\left(1-\xi^{2}\right)(1+\eta) \\
2(1-\xi)\left(1-\eta^{2}\right)
\end{array}\right] .
$$

The nodal bending strain can be written as in

$$
\begin{aligned}
& \left\{\varepsilon_{b}^{0}\right\}=\left[\begin{array}{c}
u_{0, x}(x, y) \\
v_{0, x}(x, y) \\
u_{0, x}(x, y)+v_{0, x}(x, y) \\
\phi_{x, x}(x, y) \\
\phi_{y, y}(x, y) \\
\phi_{x, y}(x, y)+\phi_{y, x}(x, y)
\end{array}\right] \\
& =\sum_{i=1}^{8}\left[\begin{array}{ccccc}
\varphi_{i}^{e} & 0 & 0 & 0 & 0 \\
0 & \varphi_{i}^{e} & 0 & 0 & 0 \\
\varphi_{i}^{e} & \varphi_{i}^{e} & 0 & 0 & 0 \\
0 & 0 & 0 & \varphi_{i}^{e} & 0 \\
0 & 0 & 0 & 0 & \varphi_{i}^{e} \\
0 & 0 & 0 & \varphi_{i}^{e} & \varphi_{i}^{e}
\end{array}\right]\left[\begin{array}{c}
u_{j} \\
v_{j} \\
w_{j} \\
s_{j 1} \\
s_{j 2}
\end{array}\right] \\
& \text { Or }\left\{\varepsilon_{b}^{0}\right\}=\sum_{i=1}^{8}\left[B_{b j}\right]\left\{u_{j}^{0}\right\} .
\end{aligned}
$$


The nodal shearing strain can be written as in

$$
\begin{aligned}
&\left\{\varepsilon_{s}^{0}\right\}=\left[\begin{array}{l}
w_{0, x}(x, y)+\phi_{x}(x, y) \\
w_{0, y}(x, y)+\phi_{y}(x, y)
\end{array}\right] \\
&=\sum_{i=1}^{8}\left[\begin{array}{lllll}
0 & 0 & \varphi_{i}^{e} & \varphi_{i}^{e} & 0 \\
0 & 0 & \varphi_{i}^{e} & 0 & \varphi_{i}^{e}
\end{array}\right]\left[\begin{array}{c}
u_{j} \\
v_{j} \\
w_{j} \\
s_{j 1} \\
s_{j 2}
\end{array}\right] \\
& \text { Or }\left\{\varepsilon_{s}^{0}\right\}=\sum_{i=1}^{8}\left[B_{s j}\right]\left\{u_{j}^{0}\right\},
\end{aligned}
$$

where $\left[B_{b j}\right]$ is the curvature-displacement matrix, $\left[B_{s j}\right]$ is the shear strain-displacement matrix, and $\left\{u_{j}^{0}\right\}$ are the nodal degrees of freedom.

The total potential energy can be given in

$$
\begin{aligned}
\Pi= & \left(0.5 \int_{A}\left\{u^{o}\right\}^{T}\left[B_{b}\right]^{T}\left[D E_{b}\right]\left\{u^{o}\right\}\left[B_{b}\right] d A\right. \\
& \left.-\int_{A}\left\{u^{o}\right\}^{T}\left[B_{b}\right]^{T}\left[D T_{b}\right] d A\right) \\
& +0.5 \int_{A}\left\{u^{o}\right\}^{T}\left[B_{s}\right]^{T}\left[D E_{s}\right]\left\{u^{o}\right\}\left[B_{s}\right] d A \\
& -\int_{A}\left\{u^{o}\right\}^{T}\left[B_{s}\right]^{T}\left[D T_{s}\right] d A \\
& -\Sigma\{P\}\left\{u^{o}\right\}^{T} .
\end{aligned}
$$

The minimum potential energy principle states that

$$
\begin{aligned}
\delta \Pi= & \left(\int_{A}\left[B_{b}\right]^{T}\left[D E_{b}\right]\left[B_{b}\right] d A\right)\left\{u^{o}\right\} \\
& +\left(\int_{A}\left[B_{s}\right]^{T}\left[D E_{s}\right]\left[B_{s}\right] d A\right)\left\{u^{o}\right\} \\
& -\int_{A}\left[B_{b}\right]^{T}\left[D T_{b}\right] d A \\
& -\int_{A}\left[B_{s}\right]^{T}\left[D T_{s}\right] d A-\sum\{P\}\left[\varphi_{i}^{e}\right]^{T}=0 .
\end{aligned}
$$

In another form,

$$
\left[\left[K_{b}\right]+\left[K_{s}\right]\right]\left\{u^{o}\right\}=\left\{F_{T}\right\}+\{P\}
$$

where $\left[K_{b}\right],\left[K_{s}\right]$ are the element bending and shear stiffness matrices, respectively, defined as in (25a) and (25b). $\left\{F_{T}\right\}$,
$\{P\}$ are the element thermal and mechanical load vectors, respectively, defined as in (26a), (26b), and (26c). Consider

$$
\begin{gathered}
{\left[K_{b}\right]=\int_{A}\left[B_{b}\right]^{T}\left[D E_{b}\right]\left[B_{b}\right] d A,} \\
{\left[K_{s}\right]=\int_{A}\left[B_{s}\right]^{T}\left[D E_{s}\right]\left[B_{s}\right] d A} \\
\{P\}=\int_{A}\left[\varphi_{i}^{e}\right]^{T}\{\sigma\} d A \\
\left\{F_{T b}\right\}=\int_{A}\left[B_{b}\right]^{T}\left[D T_{b}\right] d A, \\
\left\{F_{T s}\right\}=\int_{A}\left[B_{s}\right]^{T}\left[D T_{s}\right] d A .
\end{gathered}
$$

Substituting (20) and (21) into (9) and (11), the bending and shear strain vectors can be obtained. The normal stress components can be determined as in

$$
\begin{aligned}
{\left[\begin{array}{c}
\sigma_{x x} \\
\sigma_{y y} \\
\sigma_{x y}
\end{array}\right]=} & {\left[\begin{array}{ccc}
\overline{Q_{11}} & \overline{Q_{12}} & 0 \\
\overline{Q_{12}} & \overline{Q_{22}} & 0 \\
0 & 0 & \overline{Q_{66}}
\end{array}\right] } \\
& \times\left[\left[\begin{array}{c}
\varepsilon_{x x} \\
\varepsilon_{y y} \\
\gamma_{x y}
\end{array}\right]-\left[\begin{array}{c}
\alpha(z) \delta T(z) \\
\alpha(z) \delta T(z) \\
0
\end{array}\right]\right] \\
\text { Or }\left\{\sigma_{b}\right\} & =\left[D_{b}\right]\left\{\varepsilon_{b}\right\} .
\end{aligned}
$$

The shear stress components are determined as in

$$
\left[\begin{array}{c}
\sigma_{y z} \\
\sigma_{x z}
\end{array}\right]=\left[\begin{array}{cc}
\overline{Q_{44}} & 0 \\
0 & \overline{Q_{55}}
\end{array}\right]\left[\begin{array}{l}
\gamma_{x z}(x, y, z) \\
\gamma_{y z}(x, y, z)
\end{array}\right]\left[\left[\begin{array}{l}
\gamma_{y z} \\
\gamma_{x z}
\end{array}\right]-\left[\begin{array}{l}
0 \\
0
\end{array}\right]\right]
$$

Or $\left\{\sigma_{s}\right\}=\left[D_{s}\right]\left\{\varepsilon_{s}\right\}$.

\section{Numerical Examples}

To ascertain the accuracy and proficiency of the present finite element formulation, two examples have been analysed for thermomechanical deformations of the FGM plates. In this section, the finite element formulation of FGM plate described in previous section has been applied to a few problems to test its validity, versatility, and accuracy.

Example 1. The results are compared with those given by Ferreira et al. [8] in which meshless collocation method and first order shear deformation theory have been used. A square $(1 \mathrm{~m} \times 1 \mathrm{~m})$ simply supported FGM plate is considered for the investigation. The plate is made of a ceramic material $\left(\mathrm{ZrO}_{2}: E=151 \mathrm{GPa}, \nu=0.3\right)$ at the top surface and metallic material (Al:E $=70 \mathrm{Gpa}, \nu=0.3$ ) at the bottom surface. The length to thickness ratio $(a / h)$ was taken to be 20. Volume fraction exponent studied was $n=0$; pure ceramic $0.5,1.0,2$, and $\propto$; pure metal. Where $E$ is modulus of elasticity and $\nu$ is Poisson's ratio, the FGM plate problem with 
TABLE 1: Transverse displacement of a simply supported (SSSS) square FGM plate subjected to UDL.

\begin{tabular}{lccc}
\hline $\begin{array}{l}\text { Volume } \\
\text { fraction } \\
\text { exponent }(n)\end{array}$ & $\begin{array}{c}\text { Transverse displacement } \overline{u_{z}}=u_{z} / h \\
\text { Ferreira et al. } \\
{[8]}\end{array}$ & Present results & $\begin{array}{c}\% \\
\text { Difference }\end{array}$ \\
\hline Ceramic (0) & 0.0205 & 0.0203 & 0.97 \\
0.5 & 0.0262 & 0.0264 & 0.76 \\
1 & 0.0294 & 0.0297 & 1.02 \\
2 & 0.0323 & 0.0326 & 0.93 \\
Metal $(\propto)$ & 0.0443 & 0.0447 & 0.90 \\
\hline
\end{tabular}

abovementioned inputs is solved by proposed finite element formulation, implemented through ANSYS Software. The properties were calculated using power law function and external mechanical load in the form of uniformly distributed load which have been applied with intensity of $10 \mathrm{kN} / \mathrm{m}^{2}$. The numerical solution of this FGM plate for nondimensional transverse displacement $\overline{u_{z}}=u_{z} / h$ is computed for different values of volume fraction exponent " $n$." These results are reported in Table 1 .

The comparison of present results with those of Ferreira et al.s [8] shows that the results obtained by proposed finite element methodology is in good agreement with published results. The difference between the two results is nearly $1 \%$.

Example 2. In this example, the results are compared with those given by Chi and Chung [10] in which classical plate theory and Fourier series expansion have been used. A simply supported FGM plate is considered for the investigation. The aspect ratio $(a / b)$ of the plate in which $a=0.1 \mathrm{~m}$ and " $b$ " is kept varying. Also the length to thickness ratio $a / h$ is taken as 50. The properties at the top surface are $E=21 \mathrm{GPa}$, $v=0.3$ and those at the bottom surface are $E=210 \mathrm{GPa}$, $v=0.3$. Volume fraction exponent studied was $n=2$ where $E$ is modulus of elasticity and $v$ is Poisson's ratio. The FGM plate problem with abovementioned inputs is solved by proposed finite element formulation, implemented through ANSYS Software. The properties were calculated using sigmoid law function and external mechanical load in the form of uniformly distributed load which have been applied with intensity of $10 \mathrm{kN} / \mathrm{m}^{2}$. In order to study the convergence, nondimensional transverse displacement $\overline{u_{z}}=u_{z} / h$ and nondimensional tensile stress $\overline{S_{y}}=S_{y} / p$ are compared with those of the published results. The comparison of present results with Chi and Chung's [10] are presented in Figures 3 and 4 .

Figures 3 and 4 show the variation of maximum transverse displacement and maximum tensile stress for varying aspect ratios $(a / b)$. An excellent agreement between the present and published results can be observed. The results show that the performance of the present formulation is very good in terms of solution accuracy.

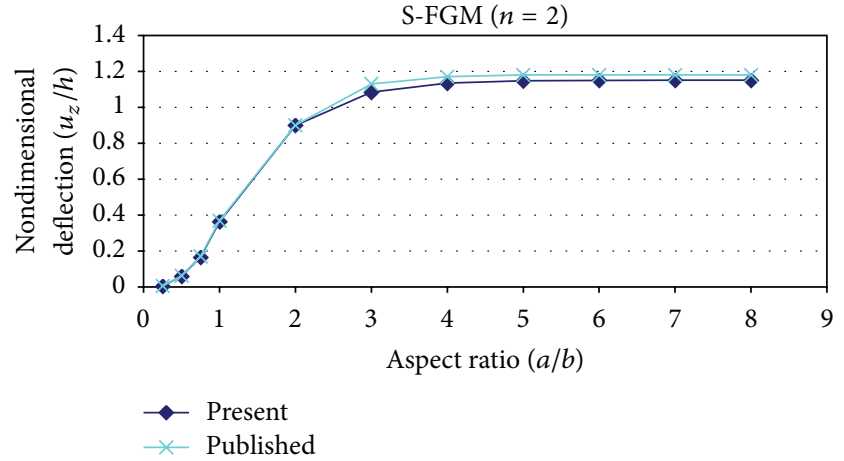

FIGURE 3: Maximum transverse displacement of an S-FGM plate versus aspect ratio $(a / b)$.

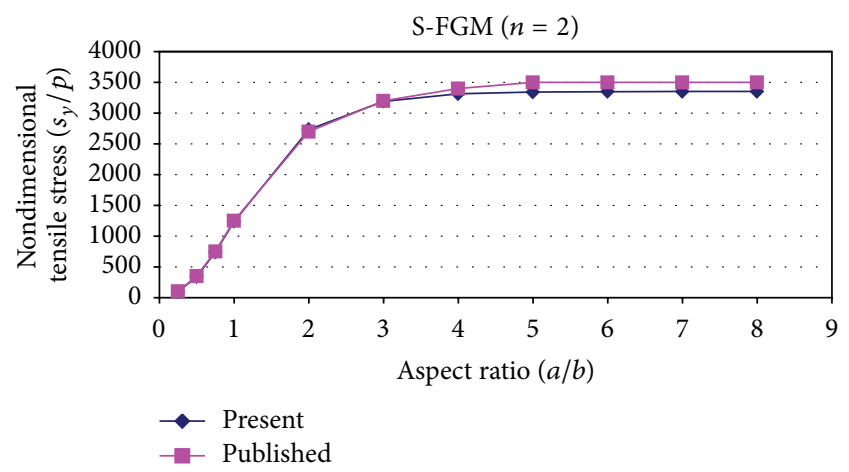

FIGURE 4: Maximum tensile stress of an S-FGM plate versus aspect ratio $(a / b)$.

\section{Thermal and Thermomechanical Analysis}

The thermal and thermomechanical analysis is conducted for FGM made of combination of metal and ceramic. The metal and ceramic chosen are aluminium and zirconia, respectively. Young's modulus for aluminium is $70 \mathrm{GPa}$ and that for zirconia is $151 \mathrm{GPa}$. The coefficient of thermal expansion for aluminium is $23 \times 10^{-6} /{ }^{\circ} \mathrm{C}$ and that for zirconia is $10 \times 10^{-6} /{ }^{\circ} \mathrm{C}$. Poisson's ratio for both the materials was chosen to be 0.3 . The effect of Poisson's ratio on the deformation is much less as compared to that of Young's modulus [1]. Thermal analysis was performed by applying thermal load on the FGM plate. The ceramic top surface is exposed to a temperature of $100^{\circ} \mathrm{C}$. The lower metallic surface and all the edges are kept at a temperature of $0^{\circ} \mathrm{C}$. The thermomechanical analysis has been performed by applying uniformly distributed load $\left(1 E 6 \mathrm{~N} / \mathrm{m}^{2}\right)$ along with thermal load on FGM plate for various boundary conditions. Various boundary conditions of plate used for the analysis are as follows: all edges are simply supported (SSSS), all edges are clamped (CCCC), alternate edges are simply supported and clamped (SCSC), alternate edges are clamped and free (CFCF), two edges are clamped and two are free (CCFF), two edges are clamped and two are simply supported (CCSS), two edges are simply supported and two are free (SSFF), three edges are simply supported and one is clamped (SSSC), three edges are simply supported and 
one is free (SSSF), and two edges are simply supported, one edge is clamped, and one is kept free (SSCF). A square FGM plate is considered here. The thickness of the plate $(h)$ is taken as $0.02 \mathrm{~m}$ and the side lengths are taken as $1 \mathrm{~m}$; that is, aspect ratio is taken unity and the length to thickness ratio is 50 . The uniformly distributed load (udl) was equal to $1 \times 10^{6} \mathrm{~N} / \mathrm{m}^{2}$. The analysis is performed for E-FGM and for various values of the volume fraction exponent $(n)$ in P-FGM and S-FGM. The results are presented in terms of nondimensional parameters, that is, nondimensional deflection $\left(\overline{u_{z}}\right)$, nondimensional tensile stress $\left(\overline{\sigma_{x}}\right)$, and nondimensional shear stress $\left(\overline{\sigma_{x y}}\right)$. follows.

The various nondimensional parameters used are as

Nondimensional deflection $\overline{u_{z}}=u_{z} / h$, nondimensional tensile stress $\left(\overline{\sigma_{x}}\right)=\sigma_{x} / p_{o}$, and nondimensional shear stress $\left(\overline{\sigma_{x y}}\right)=\sigma_{x y} / p_{o}$.

" $u_{z}$ " is deflection, " $\sigma$ " is stress, " $h$ " is plate thickness, " $a$ " and " $b$ " are side lengths of plate, and " $p_{0}$ " is applied load $\left(1 E 6 \mathrm{~N} / \mathrm{m}^{2}\right)$.

The material properties of the FGM vary throughout the thickness; the numerical model is to be broken up into number of "layers" in order to capture the change in properties. These "layers" are of finite thickness and are treated like isotropic materials. Material properties are calculated using various volume fraction distribution laws. The "layers" and their associated properties are then layered together to establish the through-thickness variation of material properties. Although the layered structure does not reflect the gradual change in material properties, a sufficient number of "layers" can reasonably approximate the material gradation.

In this paper, the modeling and analysis of FGM plate is carried out using ANSYS-APDL Software. ANSYS offers a number of elements to choose from for the modeling of gradient materials. An eight-node quadratic Lagrange element with six degrees of freedom at each node for the present model is used. The FGM characteristics under thermal and thermomechanical loads are studied on a flat plate. Based on the established approach and analysis $100 \times 100$ mesh has been used for the analysis. These have been used for computing results unless it is stated otherwise.

5.1. Variation of Boundary Conditions in Thermal Environment. This section discusses the results of the analyses performed on FGM plate with various boundary conditions subject to constant thermal environment. The results are presented in terms of nondimensional parameters, that is, nondimensional deflection $\left(\overline{u_{z}}\right)$, nondimensional tensile stress $\left(\overline{\sigma_{x}}\right)$, and nondimensional shear stress $\left(\overline{\sigma_{x y}}\right)$.

5.1.1. Nondimensional Deflection $\left(\overline{u_{z}}\right)$. Tables 2 and 3 show the nondimensional deflection $\overline{u_{z}}$ for various boundary conditions of a square plate in constant thermal environment for P-FGM, S-FGM, and E-FGM, respectively. In case of P-FGM and S-FGM, the comparison of various values of volume fraction exponent $(n)$ has been presented.

The following can be observed from Tables 2 and 3.

(a) The metal plate has the largest deflection for all the boundary conditions considered here as compared to the other FGM plate. The deflection values of FGM plate are much lower than those of fully metal plate. This clearly shows that the FGM plate can resist hightemperature conditions very well.

(b) The nondimensional deflection in the ceramic rich portion may be comparable to that in the metal rich region, because the ceramic has a lower coefficient of thermal expansion than that of the metal. Hence, the nondimensional deflection depends on the product of the temperature and the thermal expansion coefficient. Therefore, the response of the graded plate is not intermediate to the metal and ceramic plate.

(c) The maximum deflection occurs for clamped free (CCFF) boundary conditions and minimum deflection occurs for clamped (CCCC) boundary condition among all the cases considered here.

5.1.2. Nondimensional Tensile Stress $\left(\overline{\sigma_{x}}\right)$. Tables 4 and 5 show the variation of nondimensional tensile stress $\left(\overline{\sigma_{x}}\right)$ for various boundary conditions of a square plate in thermal environment for P-FGM, S-FGM, and E-FGM, respectively. In case of P-FGM and S-FGM, the comparison of various values of volume fraction exponent $(n)$ has been presented.

A close study of Tables 4 and 5 reveals the following.

(a) The nondimensional tensile stress in the ceramic rich portion may be comparable to that in the metal rich region, because the ceramic has a lower coefficient of thermal expansion than the metal and, at the same time, ceramic has more stiffness than that of the metal. Hence, the nondimensional tensile stress depends on the product of the modulus of elasticity and the thermal expansion coefficient. Therefore, the response of the graded plate is not intermediate to the metal and ceramic plate.

(b) The tensile stress increases with increasing volume fraction exponent " $n$ " for the FGM plate.

(c) The maximum tensile stress occurs for simply supported clamped free (SSCF) boundary conditions and minimum tensile stress occurs for clamped free (CFCF) boundary condition among all the cases considered here.

5.1.3. Nondimensional Shear Stress $\left(\overline{\sigma_{x y}}\right)$. Tables 6 and 7 show the variation of nondimensional shear stress $\left(\overline{\sigma_{x y}}\right)$ for various boundary conditions of a square plate in thermal environment for P-FGM, S-FGM, and E-FGM, respectively. In case of P-FGM and S-FGM, the comparison of various values of volume fraction exponent $(n)$ has been presented.

The following can be observed from Tables 6 and 7.

(a) The isotropic ceramic and metal plate has the lowest shear stress for all the boundary conditions considered here.

(b) The shear stress becomes higher with increasing $n$ for the FGM plates.

(c) The maximum shear stress occurs for simply supported clamped (SSSC) boundary conditions and 
TABLE 2: Nondimensional deflection $\left(\overline{\mathcal{u}_{z}}\right)$ for various boundary conditions of a square plate in thermal environment for P-FGM and E-FGM.

\begin{tabular}{|c|c|c|c|c|c|c|c|c|c|c|c|}
\hline \multirow{2}{*}{$\mathrm{BC}$} & \multicolumn{10}{|c|}{ P-FGM } & \multirow{2}{*}{ E-FGM } \\
\hline & $n=0$ & 0.1 & 0.2 & 0.5 & 1 & 2 & 5 & 10 & 100 & $\propto$ & \\
\hline SSSS & 0.46 & 0.10 & 0.15 & 0.23 & 0.29 & 0.33 & 0.35 & 0.41 & 0.46 & 0.52 & 0.30 \\
\hline CCCC & 0.01 & 0.00 & 0.00 & 0.01 & 0.01 & 0.01 & 0.01 & 0.01 & 0.01 & 0.01 & 0.01 \\
\hline SCSC & 0.10 & 0.02 & 0.03 & 0.05 & 0.06 & 0.07 & 0.08 & 0.09 & 0.10 & 0.11 & 0.07 \\
\hline CFCF & 0.22 & 0.05 & 0.07 & 0.11 & 0.14 & 0.16 & 0.17 & 0.20 & 0.22 & 0.25 & 0.15 \\
\hline CCFF & 1.98 & 0.44 & 0.65 & 1.01 & 1.25 & 1.40 & 1.52 & 1.75 & 1.97 & 2.22 & 1.29 \\
\hline CCSS & 0.18 & 0.04 & 0.06 & 0.09 & 0.11 & 0.13 & 0.14 & 0.16 & 0.18 & 0.20 & 0.12 \\
\hline SSFF & 1.77 & 0.40 & 0.58 & 0.90 & 1.11 & 1.25 & 1.35 & 1.56 & 1.76 & 1.98 & 1.15 \\
\hline SSSC & 0.27 & 0.06 & 0.09 & 0.14 & 0.17 & 0.19 & 0.21 & 0.24 & 0.27 & 0.30 & 0.18 \\
\hline SSSF & 0.63 & 0.14 & 0.21 & 0.32 & 0.39 & 0.44 & 0.48 & 0.55 & 0.62 & 0.70 & 0.41 \\
\hline SSCF & 0.27 & 0.06 & 0.09 & 0.14 & 0.17 & 0.19 & 0.21 & 0.24 & 0.27 & 0.30 & 0.18 \\
\hline
\end{tabular}

TABLE 3: Nondimensional deflection $\left(\overline{u_{z}}\right)$ for various boundary conditions of a square plate in thermal environment for S-FGM.

\begin{tabular}{|c|c|c|c|c|c|c|c|c|c|c|}
\hline \multirow{2}{*}{ BC } & \multicolumn{10}{|c|}{ S-FGM } \\
\hline & $n=0$ & 0.1 & 0.2 & 0.5 & 1 & 2 & 5 & 10 & 100 & $\propto$ \\
\hline SSSS & 0.46 & 0.10 & 0.12 & 0.14 & 0.19 & 0.21 & 0.25 & 0.30 & 0.35 & 0.52 \\
\hline CCCC & 0.01 & 0.00 & 0.00 & 0.00 & 0.00 & 0.00 & 0.01 & 0.01 & 0.01 & 0.01 \\
\hline SCSC & 0.10 & 0.02 & 0.03 & 0.03 & 0.04 & 0.05 & 0.05 & 0.07 & 0.08 & 0.11 \\
\hline CFCF & 0.22 & 0.05 & 0.06 & 0.07 & 0.09 & 0.10 & 0.12 & 0.15 & 0.17 & 0.25 \\
\hline CCFF & 1.98 & 0.42 & 0.50 & 0.62 & 0.82 & 0.89 & 1.06 & 1.28 & 1.50 & 2.22 \\
\hline CCSS & 0.18 & 0.04 & 0.05 & 0.06 & 0.07 & 0.08 & 0.10 & 0.12 & 0.14 & 0.20 \\
\hline SSFF & 1.77 & 0.38 & 0.45 & 0.55 & 0.73 & 0.79 & 0.95 & 1.15 & 1.34 & 1.98 \\
\hline SSSC & 0.27 & 0.06 & 0.07 & 0.08 & 0.11 & 0.12 & 0.15 & 0.18 & 0.21 & 0.30 \\
\hline SSSF & 0.63 & 0.13 & 0.16 & 0.20 & 0.26 & 0.28 & 0.34 & 0.41 & 0.48 & 0.70 \\
\hline SSCF & 0.27 & 0.06 & 0.07 & 0.08 & 0.11 & 0.12 & 0.15 & 0.18 & 0.20 & 0.30 \\
\hline
\end{tabular}

TABLE 4: Nondimensional tensile stress $\left(\overline{\sigma_{x}}\right)$ for various boundary conditions $(\mathrm{BC})$ of a square plate in thermal environment for P-FGM and E-FGM.

\begin{tabular}{|c|c|c|c|c|c|c|c|c|c|c|c|}
\hline \multirow{2}{*}{$\mathrm{BC}$} & \multicolumn{10}{|c|}{ P-FGM } & \multirow{2}{*}{ E-FGM } \\
\hline & $n=0$ & 0.1 & 0.2 & 0.5 & 1 & 2 & 5 & 10 & 100 & $\propto$ & \\
\hline SSSS & 8.03 & 19.10 & 22.04 & 27.87 & 37.40 & 43.25 & 68.56 & 86.49 & 106.73 & 12.34 & 37.90 \\
\hline СССС & 41.82 & 99.43 & 114.71 & 145.09 & 194.67 & 225.14 & 356.86 & 450.21 & 555.57 & 64.25 & 197.27 \\
\hline SCSC & 14.42 & 34.29 & 39.57 & 50.04 & 67.14 & 77.65 & 123.08 & 155.28 & 191.62 & 22.16 & 68.04 \\
\hline CFCF & 4.66 & 11.08 & 12.79 & 16.17 & 21.70 & 25.10 & 39.78 & 50.18 & 61.93 & 7.16 & 21.99 \\
\hline CCFF & 29.22 & 69.47 & 80.15 & 101.38 & 136.02 & 157.31 & 249.34 & 314.57 & 388.19 & 44.90 & 137.84 \\
\hline CCSS & 9.08 & 21.59 & 24.91 & 31.51 & 42.28 & 48.89 & 77.50 & 97.77 & 120.65 & 13.95 & 42.84 \\
\hline SSFF & 23.65 & 56.22 & 64.87 & 82.05 & 110.08 & 127.31 & 201.79 & 254.58 & 314.16 & 36.33 & 111.55 \\
\hline SSSC & 5.73 & 13.62 & 15.71 & 19.87 & 26.66 & 30.83 & 48.87 & 61.65 & 76.08 & 8.80 & 27.01 \\
\hline SSSF & 50.08 & 119.06 & 137.37 & 173.75 & 233.11 & 269.60 & 427.33 & 539.12 & 665.29 & 76.94 & 236.23 \\
\hline SSCF & 52.03 & 123.71 & 142.73 & 180.52 & 242.21 & 280.12 & 444.00 & 560.16 & 691.25 & 79.95 & 245.45 \\
\hline
\end{tabular}

minimum shear stress occurs for clamped (CCCC) boundary condition among all the cases considered here.

The nondimensional deflection, tensile stress, and shear stress for S-FGM remain closer for various values of " $n$ " as compared to those of $\mathrm{P}-\mathrm{FGM}$ since material gradation is more uniform in S-FGM as compared to P-FGM.

5.2. Comparison of P-FGM, S-FGM, E-FGM, Ceramic, and Metal. It is also interesting to see the comparison of various parameters like nondimensional deflection, tensile stress, 
TABLE 5: Nondimensional tensile stress $\left(\overline{\sigma_{x}}\right)$ for various boundary conditions (BC) of a square plate in thermal environment for S-FGM.

\begin{tabular}{|c|c|c|c|c|c|c|c|c|c|c|}
\hline \multirow{2}{*}{$\mathrm{BC}$} & \multicolumn{10}{|c|}{ S-FGM } \\
\hline & $n=0$ & 0.1 & 0.2 & 0.5 & 1 & 2 & 5 & 10 & 100 & $\propto$ \\
\hline SSSS & 8.03 & 18.34 & 25.00 & 31.04 & 37.40 & 40.04 & 43.60 & 45.60 & 47.44 & 12.34 \\
\hline СССС & 41.82 & 95.49 & 130.16 & 161.59 & 194.67 & 208.44 & 226.95 & 237.36 & 246.93 & 64.25 \\
\hline SCSC & 14.42 & 32.93 & 44.89 & 55.73 & 67.14 & 71.89 & 78.28 & 81.87 & 85.17 & 22.16 \\
\hline $\mathrm{CFCF}$ & 4.66 & 10.64 & 14.51 & 18.01 & 21.70 & 23.23 & 25.30 & 26.46 & 27.52 & 7.16 \\
\hline CCFF & 29.22 & 66.72 & 90.94 & 112.91 & 136.02 & 145.64 & 158.58 & 165.85 & 172.53 & 44.90 \\
\hline CCSS & 9.08 & 20.74 & 28.27 & 35.09 & 42.28 & 45.27 & 49.29 & 51.55 & 53.63 & 13.95 \\
\hline SSFF & 23.65 & 54.00 & 73.60 & 91.38 & 110.08 & 117.87 & 128.33 & 134.22 & 139.63 & 36.33 \\
\hline SSSC & 5.73 & 13.08 & 17.82 & 22.13 & 26.66 & 28.54 & 31.08 & 32.50 & 33.81 & 8.80 \\
\hline SSSF & 50.08 & 114.35 & 155.86 & 193.50 & 233.11 & 249.60 & 271.77 & 284.23 & 295.69 & 76.94 \\
\hline SSCF & 52.03 & 118.81 & 161.94 & 201.06 & 242.21 & 259.34 & 282.37 & 295.32 & 307.23 & 79.95 \\
\hline
\end{tabular}

TABLE 6: Nondimensional shear stress $\left(\overline{\sigma_{x y}}\right)$ for various boundary conditions (BC) of a square plate in thermal environment for P-FGM and E-FGM.

\begin{tabular}{|c|c|c|c|c|c|c|c|c|c|c|c|}
\hline \multirow{2}{*}{ BC } & \multicolumn{10}{|c|}{ P-FGM } & \multirow{2}{*}{ E-FGM } \\
\hline & $n=0$ & 0.1 & 0.2 & 0.5 & 1 & 2 & 5 & 10 & 100 & $\propto$ & \\
\hline SSSS & 378.1 & 423.4 & 426.5 & 429.6 & 465.0 & 515.7 & 580.6 & 642.4 & 644.9 & 400.2 & 487.0 \\
\hline СССС & 97.9 & 109.6 & 110.4 & 111.2 & 120.4 & 133.5 & 150.3 & 166.3 & 166.9 & 103.6 & 126.1 \\
\hline SCSC & 324.5 & 363.4 & 366.1 & 368.6 & 399.1 & 442.6 & 498.3 & 551.3 & 553.5 & 343.4 & 418.0 \\
\hline CFCF & 237.3 & 265.7 & 267.7 & 269.5 & 291.8 & 323.6 & 364.3 & 403.1 & 404.7 & 251.1 & 305.6 \\
\hline CCFF & 238.7 & 267.3 & 269.3 & 271.2 & 293.5 & 325.6 & 366.5 & 405.5 & 407.1 & 252.6 & 307.4 \\
\hline CCSS & 331.2 & 370.9 & 373.6 & 376.3 & 407.3 & 451.8 & 508.6 & 562.7 & 564.9 & 350.5 & 426.6 \\
\hline SSFF & 224.1 & 250.9 & 252.7 & 254.5 & 275.5 & 305.6 & 344.0 & 380.6 & 382.1 & 237.1 & 288.6 \\
\hline SSSC & 397.6 & 445.2 & 448.5 & 451.7 & 488.9 & 542.3 & 610.5 & 675.5 & 678.2 & 420.8 & 512.1 \\
\hline SSSF & 351.9 & 394.0 & 396.9 & 399.7 & 432.7 & 479.9 & 540.3 & 597.8 & 600.2 & 372.4 & 453.2 \\
\hline SSCF & 258.2 & 289.1 & 291.3 & 293.3 & 317.5 & 352.2 & 396.4 & 438.7 & 440.4 & 273.2 & 332.5 \\
\hline
\end{tabular}

TABLE 7: Nondimensional shear stress $\left(\overline{\sigma_{x y}}\right)$ for various boundary conditions (BC) of a square plate in thermal environment for S-FGM.

\begin{tabular}{lcccccccccc}
\hline \multirow{2}{*}{ BC } & $n=0$ & 0.1 & 0.2 & 0.5 & 1 & 2 & 5 & 10 & 100 \\
\hline SSSS & 378.1 & 386.2 & 410.9 & 437.1 & 465.0 & 477.6 & 537.6 & 594.9 & 597.2 & 400.2 \\
CCCC & 97.9 & 100.0 & 106.3 & 113.1 & 120.4 & 123.6 & 139.2 & 154.0 & 154.6 & 103.6 \\
SCSC & 324.5 & 331.5 & 352.6 & 375.1 & 399.1 & 409.9 & 461.4 & 510.5 & 512.5 & 343.4 \\
CFCF & 237.3 & 242.3 & 257.8 & 274.3 & 291.8 & 299.7 & 337.4 & 373.3 & 374.8 & 251.1 \\
CCFF & 238.7 & 243.8 & 259.4 & 275.9 & 293.5 & 301.5 & 339.4 & 375.5 & 377.0 & 252.6 \\
CCSS & 331.2 & 338.3 & 359.9 & 382.9 & 407.3 & 418.3 & 470.9 & 521.1 & 523.1 & 350.5 \\
SSFF & 224.1 & 228.8 & 243.4 & 259.0 & 275.5 & 283.0 & 318.6 & 352.5 & 353.9 & 237.1 \\
SSSC & 397.6 & 406.1 & 432.0 & 459.6 & 488.9 & 502.2 & 565.3 & 625.5 & 628.0 & 420.8 \\
SSSF & 351.9 & 359.4 & 382.3 & 406.7 & 432.7 & 444.4 & 500.3 & 553.6 & 555.8 & 372.4 \\
SSCF & 258.2 & 263.7 & 280.5 & 298.4 & 317.5 & 326.1 & 367.1 & 406.2 & 407.8 & 273.2 \\
\hline
\end{tabular}

shear stress, transverse strain and shear strain for ceramic, metal, and FGMs following power law, sigmoid, and exponential distribution. Figures 5, 6, and 7 show the comparison graphs for pure ceramic $(n=0)$, pure metal $(n=\infty)$, P-FGM $(n=2), \mathrm{P}-\mathrm{FGM}(n=0.5), \mathrm{S}-\mathrm{FGM}(n=2), \mathrm{S}-\mathrm{FGM}(n=0.5)$, and E-FGM.

5.2.1. Nondimensional Deflection $\left(\overline{u_{z}}\right)$. The following is observed from Figures 5, 6, and 7. (a) The nondimensional deflection for the three FGMs is more than that of the ceramic and metal.

(b) The nondimensional parameters, for example, tensile stress and shear stress, for the three FGMs are less than those of the ceramic and metal.

(c) It is evident from the above comparison that P-FGM $(n=0.5)$ plate has the smallest deflection and stress among all kinds of FGM plates. The reason is 


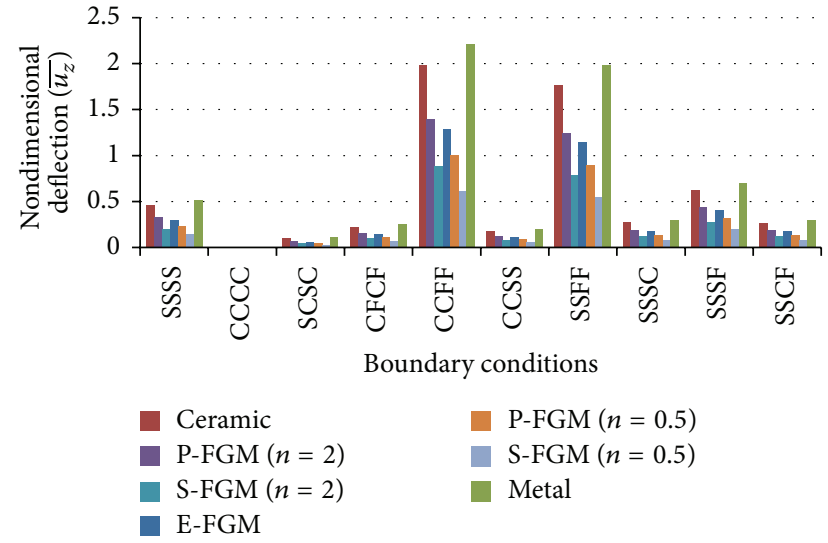

Figure 5: Nondimensional deflection $\left(\overline{u_{z}}\right)$ for various boundary conditions of a square plate for various FGMs in thermal environment.

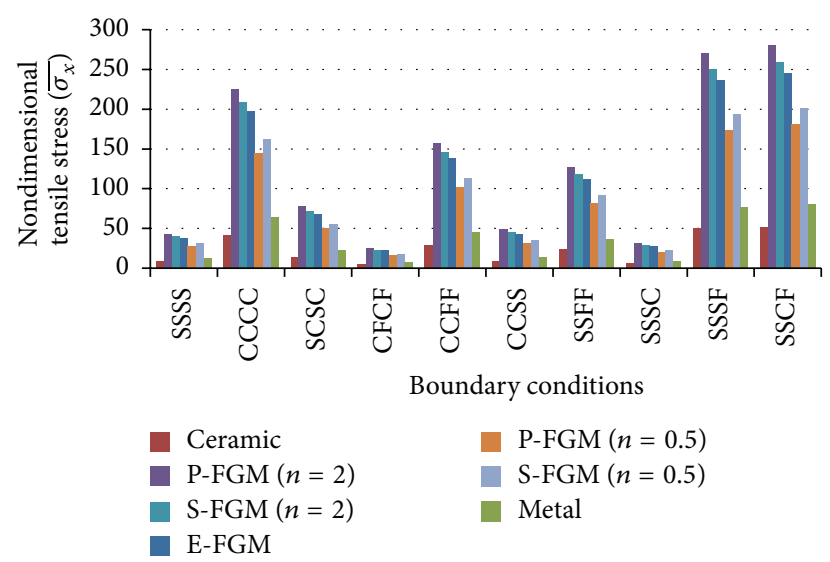

FIGURE 6: Nondimensional tensile stress $\left(\overline{\sigma_{x}}\right)$ for various boundary conditions of a square plate for various FGMs in thermal environment.

observable that the coefficient of thermal expansion of the P-FGM $(n=0.5)$ plate is more than that of EFGM plate and stiffness of the E-FGM plate is more than that of P-FGM $(n=2)$.

\subsubsection{Nondimensional Tensile Stress $\left(\overline{\sigma_{x}}\right)$. See Figure 6 .}

\subsubsection{Nondimensional Shear Stress $\left(\overline{\sigma_{x y}}\right)$. See Figure 7.}

5.3. Variation of Boundary Condition in under UDL in Thermal Environment. This section discusses the results of the analyses performed on FGM plate with various boundary conditions subject to constant UDL in thermal environment. The results are presented in terms of nondimensional parameters, that is, nondimensional deflection $\left(\overline{u_{z}}\right)$, nondimensional tensile stress $\left(\overline{\sigma_{x}}\right)$, and nondimensional shear stress $\left(\overline{\sigma_{x y}}\right)$.

5.3.1. Nondimensional Deflection $\left(\overline{u_{z}}\right)$. Tables 8 and 9 show nondimensional deflection $\left(\overline{u_{z}}\right)$ for various boundary conditions of a square plate under uniformly distributed load

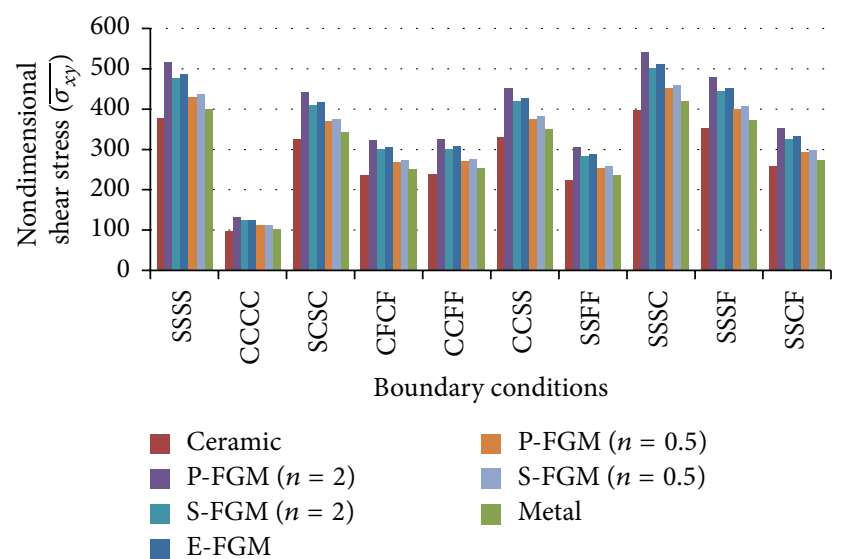

FIGURE 7: Nondimensional shear stress $\left(\overline{\sigma_{x y}}\right)$ for various boundary conditions of a square plate for various FGMs in thermal environment.

in thermal environment for P-FGM, S-FGM, and E-FGM, respectively.

A study of Tables 8 and 9 reveals the following information.

(a) The nondimensional deflection in the ceramic rich portion may be comparable to that in the metal rich region. The nondimensional deflection is maximum for the case of pure metal $(n=\infty)$ and pure ceramic $(n=0)$. The nondimensional deflection of both the metallic and the ceramic plates is higher in magnitude than the graded plates. The deflection therefore depends on the product of the temperature and the thermal expansion coefficient. Therefore, the response of the graded plates is not intermediate to the metal and ceramic plates.

(b) The deflections become higher with increasing $n$. It is observed that when thermal effect is induced, the bending response of the functionally graded plate is not necessarily intermediate to those of the metal and the ceramic plate.

(c) It is also found that the maximum deflection occurs for simply supported free (SSFF) boundary conditions and minimum deflection occurs for clamped (CCCC) boundary condition for all the cases considered here.

5.3.2. Nondimensional Tensile Stress $\left(\overline{\sigma_{x}}\right)$. Tables 10 and 11 show the variation of nondimensional tensile stress $\left(\overline{\sigma_{x}}\right)$ for various boundary conditions of a square plate under uniformly distributed load in thermal environment for PFGM, S-FGM, and E-FGM, respectively. In case of P-FGM and S-FGM, the comparison of various values of volume fraction exponent $(n)$ have been presented.

The following can be observed from Tables 10 and 11.

(a) The isotropic ceramic and metallic plates have the lowest tensile stress for all the boundary conditions 
TABLE 8: Nondimensional deflection $\left(\overline{u_{z}}\right)$ for various boundary conditions $(\mathrm{BC})$ of a square plate under udl in thermal environment for P-FGM and E-FGM.

\begin{tabular}{|c|c|c|c|c|c|c|c|c|c|c|c|}
\hline \multirow{2}{*}{ BC } & \multicolumn{10}{|c|}{ P-FGM } & \multirow{2}{*}{ E-FGM } \\
\hline & $n=0$ & 0.1 & 0.2 & 0.5 & 1 & 2 & 5 & 10 & 100 & $\propto$ & \\
\hline SSSS & 3.9 & 2.2 & 2.3 & 2.6 & 3.0 & 3.2 & 3.4 & 3.5 & 3.8 & 4.0 & 3.1 \\
\hline CССC & 1.2 & 0.6 & 0.7 & 0.7 & 0.8 & 0.9 & 1.0 & 1.0 & 1.1 & 1.2 & 0.9 \\
\hline SCSC & 1.8 & 1.0 & 1.0 & 1.2 & 1.3 & 1.4 & 1.5 & 1.6 & 1.7 & 1.9 & 1.4 \\
\hline CFCF & 2.7 & 1.4 & 1.5 & 1.6 & 1.7 & 1.9 & 2.1 & 2.3 & 2.6 & 2.9 & 1.8 \\
\hline $\mathrm{CCFF}$ & 40.7 & 21.5 & 22.3 & 24.5 & 27.1 & 29.6 & 32.4 & 34.7 & 38.9 & 42.9 & 28.0 \\
\hline CCSS & 2.1 & 1.1 & 1.2 & 1.4 & 1.5 & 1.7 & 1.8 & 1.9 & 2.0 & 2.2 & 1.6 \\
\hline SSFF & 169.3 & 91.0 & 95.3 & 111.3 & 125.4 & 136.4 & 139.2 & 148.1 & 158.6 & 178.2 & 121.8 \\
\hline SSSC & 2.7 & 1.5 & 1.6 & 1.8 & 2.0 & 2.2 & 2.4 & 2.4 & 2.6 & 2.8 & 2.1 \\
\hline SSSF & 12.1 & 6.6 & 6.9 & 7.8 & 8.7 & 9.5 & 10.2 & 10.7 & 11.7 & 12.7 & 9.0 \\
\hline SSCF & 5.6 & 3.0 & 3.2 & 3.5 & 3.9 & 4.3 & 4.6 & 4.9 & 5.4 & 5.9 & 4.0 \\
\hline
\end{tabular}

TAble 9: Nondimensional deflection $\left(\overline{u_{z}}\right)$ for various boundary conditions $(B C)$ of a square plate under udl in thermal environment for S-FGM.

\begin{tabular}{|c|c|c|c|c|c|c|c|c|c|c|}
\hline \multirow{2}{*}{$\mathrm{BC}$} & \multicolumn{10}{|c|}{ S-FGM } \\
\hline & $n=0$ & 0.1 & 0.2 & 0.5 & 1 & 2 & 5 & 10 & 100 & $\propto$ \\
\hline SSSS & 3.9 & 2.7 & 2.7 & 2.8 & 3.0 & 3.1 & 3.2 & 3.3 & 3.3 & 4.0 \\
\hline CСCC & 1.2 & 0.8 & 0.8 & 0.8 & 0.8 & 0.8 & 0.9 & 0.9 & 0.9 & 1.2 \\
\hline SCSC & 1.8 & 1.2 & 1.2 & 1.3 & 1.3 & 1.4 & 1.4 & 1.4 & 1.4 & 1.9 \\
\hline CFCF & 2.7 & 1.8 & 1.8 & 1.7 & 1.7 & 1.8 & 1.8 & 1.8 & 1.8 & 2.9 \\
\hline CCFF & 40.7 & 26.9 & 26.8 & 26.9 & 27.1 & 27.5 & 28.0 & 28.1 & 28.2 & 42.9 \\
\hline CCSS & 2.1 & 1.4 & 1.4 & 1.5 & 1.5 & 1.6 & 1.7 & 1.7 & 1.7 & 2.2 \\
\hline SSFF & 169.3 & 113.4 & 115.5 & 120.8 & 125.4 & 131.6 & 136.5 & 137.8 & 138.2 & 178.2 \\
\hline SSSC & 2.7 & 1.9 & 1.9 & 2.0 & 2.0 & 2.1 & 2.2 & 2.2 & 2.2 & 2.8 \\
\hline SSSF & 12.1 & 8.2 & 8.3 & 8.5 & 8.7 & 9.0 & 9.3 & 9.3 & 9.4 & 12.7 \\
\hline SSCF & 5.6 & 3.8 & 3.8 & 3.8 & 3.9 & 4.0 & 4.1 & 4.1 & 4.1 & 5.9 \\
\hline
\end{tabular}

TABLE 10: Nondimensional tensile stress $\left(\overline{\sigma_{x}}\right)$ for various boundary conditions $(\mathrm{BC})$ of a square plate under udl in thermal environment for P-FGM and E-FGM.

\begin{tabular}{|c|c|c|c|c|c|c|c|c|c|c|c|}
\hline \multirow{2}{*}{$\mathrm{BC}$} & \multicolumn{10}{|c|}{ P-FGM } & \multirow{2}{*}{ E-FGM } \\
\hline & $n=0$ & 0.1 & 0.2 & 0.5 & 1 & 2 & 5 & 10 & 100 & $\propto$ & \\
\hline SSSS & 400.8 & 418.9 & 421.0 & 438.7 & 479.6 & 534.5 & 570.4 & 584.2 & 613.1 & 380.7 & 488.8 \\
\hline СССС & 520.5 & 566.0 & 586.8 & 637.2 & 688.9 & 732.8 & 778.9 & 807.4 & 769.4 & 494.5 & 710.9 \\
\hline SCSC & 148.0 & 155.8 & 155.8 & 185.1 & 212.4 & 232.8 & 417.6 & 277.4 & 303.8 & 140.6 & 220.7 \\
\hline $\mathrm{CFCF}$ & 1130.4 & 1205.6 & 1244.5 & 1342.6 & 1445.5 & 1536.1 & 1632.3 & 1690.8 & 1628.1 & 1073.9 & 1472.3 \\
\hline CCFF & 4170.4 & 4381.9 & 4482.4 & 4744.8 & 5041.1 & 5330.3 & 5699.6 & 5962.2 & 5857.1 & 3961.9 & 5143.8 \\
\hline CCSS & 893.0 & 990.7 & 1037.2 & 1141.8 & 1241.5 & 1321.3 & 1388.6 & 1416.8 & 1327.7 & 848.4 & 1256.9 \\
\hline SSFF & 1249.9 & 1315.7 & 1307.7 & 1377.9 & 1506.4 & 1678.8 & 1609.6 & 1834.7 & 1925.7 & 1187.4 & 1416.5 \\
\hline SSSC & 256.0 & 269.5 & 269.9 & 282.7 & 318.1 & 358.9 & 393.1 & 408.7 & 436.1 & 243.2 & 326.3 \\
\hline SSSF & 1231.7 & 1296.5 & 1288.7 & 1300.9 & 1374.3 & 1495.6 & 1591.7 & 1636.7 & 1720.4 & 1170.1 & 1390.8 \\
\hline SSCF & 1937.0 & 2078.3 & 2148.8 & 2317.8 & 2492.4 & 2646.8 & 2808.6 & 2901.4 & 2787.5 & 1840.2 & 2525.5 \\
\hline
\end{tabular}

considered here. In the presence of the above temperature field, compression occurs at the top surface while tension is at the bottom surface. Excepting fully ceramic or fully metal plates, the stress distribution of FGM plates has a similar trend. The nondimensional tensile stress is minimum for the case of pure metal $(n=\infty)$ and pure ceramic $(n=0)$. (b) The tensile stress becomes higher with increasing $n$. This is due to the fact that the bending stiffness is the maximum for ceramic plate, while being minimal for metallic plate, and degrades continuously as $n$ increases.

(c) The nondimensional tensile stress therefore depends on the product of the temperature and the thermal 
TABLE 11: Nondimensional tensile stress $\left(\overline{\sigma_{x}}\right)$ for various boundary conditions $(\mathrm{BC})$ of a square plate under udl in thermal environment for S-FGM.

\begin{tabular}{|c|c|c|c|c|c|c|c|c|c|c|}
\hline \multirow{2}{*}{$\mathrm{BC}$} & \multicolumn{10}{|c|}{ S-FGM } \\
\hline & $n=0$ & 0.1 & 0.2 & 0.5 & 1 & 2 & 5 & 10 & 100 & $\propto$ \\
\hline SSSS & 400.8 & 490.2 & 483.6 & 475.2 & 479.6 & 500.6 & 528.0 & 535.8 & 538.4 & 380.7 \\
\hline CCCC & 520.5 & 623.0 & 636.9 & 666.2 & 688.9 & 698.9 & 698.8 & 698.5 & 698.5 & 494.5 \\
\hline SCSC & 148.0 & 217.9 & 209.7 & 196.1 & 212.4 & 222.0 & 223.1 & 222.8 & 222.4 & 140.6 \\
\hline CFCF & 1130.4 & 1346.1 & 1366.8 & 1411.1 & 1445.5 & 1459.6 & 1457.0 & 1455.2 & 1454.1 & 1073.9 \\
\hline $\mathrm{CCFF}$ & 4170.4 & 4883.3 & 4923.0 & 4997.3 & 5041.1 & 5038.1 & 5006.9 & 4998.4 & 4995.4 & 3961.9 \\
\hline CCSS & 893.0 & 1109.6 & 1137.4 & 1195.6 & 1241.5 & 1264.5 & 1267.0 & 1265.8 & 1264.5 & 848.4 \\
\hline SSFF & 1249.9 & 1469.0 & 1449.3 & 1424.1 & 1506.4 & 1572.3 & 1658.4 & 1682.8 & 1690.8 & 1187.4 \\
\hline SSSC & 256.0 & 334.0 & 326.8 & 315.8 & 318.1 & 330.8 & 343.2 & 347.8 & 349.2 & 243.2 \\
\hline SSSF & 1231.7 & 1456.7 & 1430.6 & 1386.7 & 1374.3 & 1405.3 & 1458.2 & 1473.7 & 1478.8 & 1170.1 \\
\hline SSCF & 1937.0 & 2332.1 & 2367.8 & 2439.2 & 2492.4 & 2511.2 & 2504.2 & 2499.9 & 2497.4 & 1840.2 \\
\hline
\end{tabular}

TABLE 12: Nondimensional shear stress $\left(\overline{\sigma_{x y}}\right)$ for various boundary conditions $(\mathrm{BC})$ of a square plate under udl in thermal environment for P-FGM and E-FGM.

\begin{tabular}{|c|c|c|c|c|c|c|c|c|c|c|c|}
\hline \multirow{2}{*}{ BC } & \multicolumn{10}{|c|}{ P-FGM } & \multirow{2}{*}{ E-FGM } \\
\hline & $n=0$ & 0.1 & 0.2 & 0.5 & 1 & 2 & 5 & 10 & 100 & $\propto$ & \\
\hline SSSS & 544.6 & 605.2 & 614.8 & 635.1 & 668.7 & 713.7 & 734.5 & 735.9 & 745.2 & 517.4 & 657.7 \\
\hline СССС & 129.2 & 135.5 & 139.2 & 148.2 & 157.6 & 165.9 & 175.6 & 182.4 & 178.3 & 122.7 & 160.6 \\
\hline SCSC & 294.5 & 310.0 & 322.6 & 349.7 & 379.8 & 420.4 & 294.9 & 499.9 & 468.0 & 279.8 & 351.6 \\
\hline CFCF & 365.6 & 286.2 & 287.8 & 291.8 & 304.7 & 329.0 & 351.9 & 360.0 & 369.0 & 347.4 & 296.6 \\
\hline CCFF & 750.7 & 780.3 & 800.0 & 849.8 & 904.3 & 957.3 & 1023.0 & 1065.9 & 1041.6 & 713.1 & 917.4 \\
\hline CCSS & 339.4 & 315.5 & 328.4 & 356.1 & 386.8 & 428.2 & 486.6 & 508.9 & 476.3 & 322.5 & 358.1 \\
\hline SSFF & 2745.2 & 2889.7 & 2979.2 & 3032.5 & 3193.1 & 3408.0 & 3445.8 & 3513.8 & 3558.5 & 2608.0 & 3270.0 \\
\hline SSSC & 530.3 & 558.2 & 566.8 & 584.6 & 615.0 & 658.0 & 681.8 & 685.3 & 694.3 & 503.8 & 601.7 \\
\hline SSSF & 688.4 & 724.6 & 733.1 & 753.6 & 791.9 & 842.9 & 864.4 & 867.4 & 885.5 & 653.9 & 785.2 \\
\hline SSCF & 309.2 & 286.2 & 295.3 & 315.3 & 329.9 & 332.3 & 373.1 & 401.1 & 409.5 & 293.7 & 352.3 \\
\hline
\end{tabular}

expansion coefficient. Therefore, the response of the graded plates is not intermediate to the metal and ceramic plates.

(d) It is also found that the maximum tensile stress occurs for simply supported free (CCFF) boundary conditions and minimum tensile stress occurs for clamped (SCSC) boundary condition for all the cases considered here.

5.3.3. Nondimensional Shear Stress $\left(\overline{\sigma_{x y}}\right)$. Tables 12 and 13 show the variation of nondimensional shear stress $\left(\overline{\sigma_{x y}}\right)$ for various boundary conditions of a square plate under uniformly distributed load in thermal environment for PFGM, S-FGM, and E-FGM, respectively. In case of P-FGM and S-FGM, the comparison of various values of volume fraction exponent $(n)$ has been presented.

The following can be observed from Tables 12 and 13 .

(a) The isotropic ceramic and metallic plate has the lowest shear stress for all the boundary conditions considered here. In the presence of the above temperature field, compression occurs at the top surface while tension is at the bottom surface. Excepting fully ceramic or fully metal plates, the stress distribution of FGM plates has a similar trend. The nondimensional tensile stress is minima for the case of pure metal $(n=\infty)$ and pure ceramic $(n=0)$.

(b) The shear stress becomes higher with increasing $n$. This is due to the fact that the bending stiffness is maximum for ceramic plate, while being minimal for metallic plate, and degrades continuously as $n$ increases.

(c) The response of the graded plates is not intermediate to the metal and ceramic plates.

(d) It is also found that the maximum shear stress occurs for simply supported free (SSFF) boundary conditions and minimum shear stress occurs for clamped (CCCC) boundary condition for all the cases considered here.

The nondimensional deflection, tensile stress, and shear stress for S-FGM remain closer for various values of " $n$ " as compared to those of the P-FGM since material gradation is more uniform in S-FGM as compared to P-FGM.

5.4. Comparison of P-FGM, S-FGM, E-FGM, Ceramic, and Metal. It is also interesting to see the comparison of various parameters like nondimensional deflection, tensile stress, shear stress, transverse strain, and shear strain for ceramic, 
TABLE 13: Nondimensional shear stress $\left(\overline{\sigma_{x y}}\right)$ for various boundary conditions (BC) of a square plate under udl in thermal environment for S-FGM.

\begin{tabular}{|c|c|c|c|c|c|c|c|c|c|c|}
\hline \multirow{2}{*}{$\mathrm{BC}$} & \multicolumn{10}{|c|}{ S-FGM } \\
\hline & $n=0$ & 0.1 & 0.2 & 0.5 & 1 & 2 & 5 & 10 & 100 & $\propto$ \\
\hline SSSS & 544.6 & 675.0 & 670.6 & 664.5 & 668.7 & 688.6 & 713.4 & 718.8 & 719.5 & 517.4 \\
\hline CССC & 129.2 & 150.0 & 151.7 & 155.1 & 157.6 & 158.5 & 158.4 & 158.4 & 158.4 & 122.7 \\
\hline SCSC & 294.5 & 410.5 & 408.6 & 398.5 & 379.8 & 354.4 & 328.4 & 318.6 & 313.4 & 279.8 \\
\hline CFCF & 365.6 & 330.9 & 324.6 & 312.2 & 304.7 & 304.9 & 309.4 & 310.2 & 309.9 & 347.4 \\
\hline $\mathrm{CCFF}$ & 750.7 & 875.7 & 883.1 & 896.7 & 904.3 & 903.3 & 897.3 & 895.4 & 894.6 & 713.1 \\
\hline CCSS & 339.4 & 417.9 & 416.0 & 405.8 & 386.8 & 361.0 & 334.5 & 324.6 & 319.2 & 322.5 \\
\hline SSFF & 2745.2 & 3169.0 & 3148.4 & 3119.6 & 3193.1 & 3288.1 & 3406.6 & 3432.4 & 3435.7 & 2608.0 \\
\hline SSSC & 530.3 & 629.7 & 624.2 & 614.9 & 615.0 & 629.5 & 649.1 & 653.1 & 653.2 & 503.8 \\
\hline SSSF & 688.4 & 797.3 & 792.0 & 785.3 & 791.9 & 817.8 & 850.0 & 857.6 & 859.0 & 653.9 \\
\hline SSCF & 309.2 & 337.7 & 331.4 & 315.2 & 329.9 & 350.1 & 366.4 & 372.2 & 375.1 & 293.7 \\
\hline
\end{tabular}

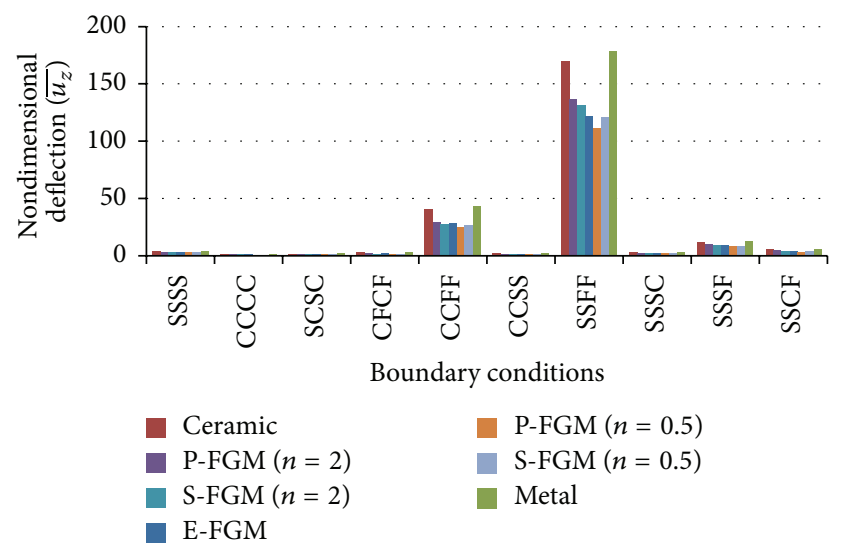

FIGURE 8: Nondimensional deflection $\left(\overline{u_{z}}\right)$ for various boundary conditions of a square plate under uniformly distributed load for various FGMs in thermal environment.

metal, and FGMs following power law, sigmoid, and exponential distribution. Figures 8,9 , and 10 show the comparison graphs for pure ceramic $(n=0)$, pure metal $(n=\infty)$, P-FGM $(n=2)$, P-FGM $(n=0.5)$, S-FGM $(n=2)$, S-FGM $(n=0.5)$, and E-FGM.

\subsubsection{Nondimensional Deflection $\left(\overline{u_{z}}\right)$. See Figure 8 .}

\subsubsection{Nondimensional Tensile Stress $\left(\overline{\sigma_{x}}\right)$. See Figure 9.}

The following is observed from Figures 8, 9, and 10:

(a) The nondimensional parameters deflection, strain, and shear strain for the three FGMs are maximum for the ceramic and metal.

(b) The nondimensional parameters tensile stress and shear stress for the three FGMs are minimum for the ceramic and metal.

(c) P-FGM ( $n=0.5$ ) plate has the smallest deflection and stress among all kinds of FGM plate. The reason is observable in which the stiffness of the P-FGM $(n=0.5)$ plate is more than that of E-FGM plate and

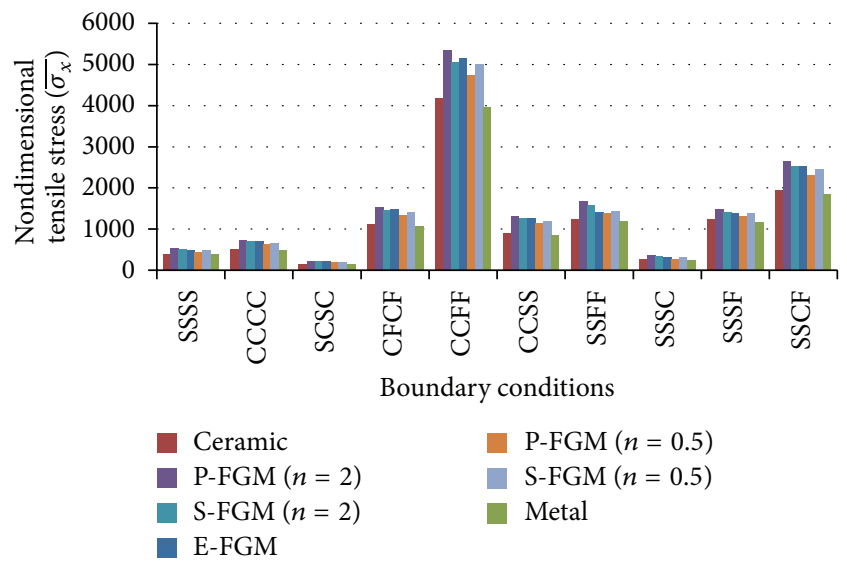

FIGURE 9: Nondimensional tensile stress $\left(\overline{\sigma_{x}}\right)$ for various boundary conditions of a square plate under uniformly distributed load for various FGMs in thermal environment.

stiffness of the E-FGM plate is more than that of P$\operatorname{FGM}(n=2)$.

\subsubsection{Nondimensional Shear Stress $\left(\overline{\sigma_{x y}}\right)$. See Figure 10.}

\section{Conclusion and Future Scope}

(a) It is seen that the intermediate response of graded plates under thermal and thermomechanical loads is quite different from the pure mechanical load [20]. The deflections become higher with increasing $n$. It is observed that when thermal effect is induced, the bending response of the functionally graded plate is not necessarily intermediate to those of the metal and the ceramic plate.

(b) The nondimensional deflection of isotropic plates (pure metal and pure ceramic) is higher in magnitude than the graded plates. The deflection therefore depends on the product of the temperature and the thermal expansion coefficient. Therefore, the response of the graded plates is not intermediate to the metal and ceramic plates. It is clear that the FGM plates can resist high-temperature conditions very well. 


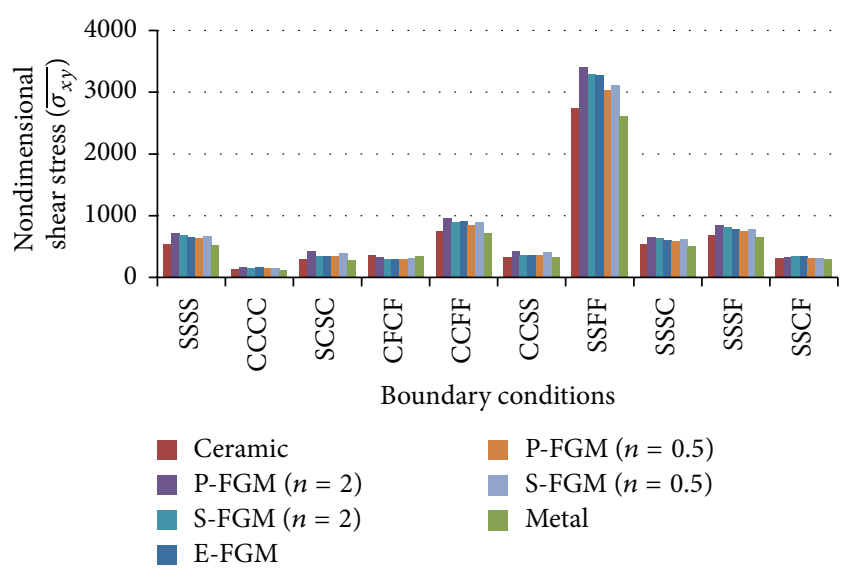

FIGURE 10: Nondimensional shear stress $\left(\overline{\sigma_{x y}}\right)$ for various boundary conditions of a square plate under uniformly distributed load for various FGMs in thermal environment.

(c) The maximum deflection occurs for clamped free (CCFF) boundary conditions and minimum deflection occurs for clamped (CCCC) boundary condition under thermal load while, under thermomechanical load, the maximum deflection occurs for simply supported free (SSFF) boundary conditions and minimum deflection occurs for clamped (CCCC) boundary condition.

(d) The maximum tensile stress under thermal load occurs for simply supported clamped free (SSCF) boundary conditions and minimum tensile stress occurs for clamped free (CFCF) boundary condition while, under thermomechanical load, the maximum tensile stress occurs for simply supported free (CCFF) boundary conditions and minimum tensile stress occurs for clamped (SCSC) boundary condition.

(e) The isotropic ceramic and metallic plates have the lowest tensile and shear stress for all the boundary conditions considered here. In the presence of the above temperature field, compression occurs at the top surface while tension is at the bottom surface. Excepting fully ceramic or fully metal plates, the stress distribution of FGM plates has a similar trend.

(f) The maximum shear stress under thermal load occurs for simply supported clamped (SSSC) boundary conditions and minimum shear stress occurs for clamped (CCCC) boundary conditions while, under thermomechanical load, maximum shear stress occurs for simply supported free (SSFF) boundary conditions and minimum shear stress occurs for clamped (CCCC) boundary condition.

(g) The nondimensional deflection, nondimensional tensile stress, and nondimensional shear stress for S-FGM remain closer for various values of " $n$ " as compared to those of the P-FGM.

The efforts taken in this work are to solve and analyze FGM plate with various loadings and boundary conditions should pave a way for more research in the future.

(1) More complex geometries can be taken for analysis. The geometries to be analyzed can be selected in such a way that they could be used in real-time engineering in the future.
(2) A further investigation of functionally graded plate structures with material properties varying in directions other than through the thickness is recommended.

(3) Since the prediction of the thermomechanical properties is not a simple task, the techniques for estimating effective material properties of functionally graded material structure are required.

\section{Conflict of Interests}

The authors declare that there is no conflict of interests regarding the publication of this paper.

\section{References}

[1] F. Delale and F. Erdogan, "The crack problem for a nonhomogeneous plane," NASA Contractor Report, Lehigh University, 1982.

[2] G. N. Praveen and J. N. Reddy, "Nonlinear transient thermoelastic analysis of functionally graded ceramic-metal plates," International Journal of Solids and Structures, vol. 35, no. 33, pp. 4457-4476, 1998.

[3] J. N. Reddy, "Thermomechanical behavior of functionally graded materials," Final Report for Afosr Grant F49620-95-10342, Cml Report 98-01, 1998.

[4] Z.-Q. Cheng and R. C. Batra, "Three-dimensional thermoelastic deformations of a functionally graded elliptic plate," Composites Part B: Engineering, vol. 31, no. 2, pp. 97-106, 2000.

[5] J. N. Reddy and Q. C. Zhen, "Three-dimensional thermo mechanical deformations of functionally graded rectangular plates," European Journal of Mechanics A/Solids, vol. 20, no. 5, pp. 841-855, 2001.

[6] L. F. Qian and R. C. Batra, "Transient thermoelastic deformations of a thick functionally graded plate," Journal of Thermal Stresses, vol. 27, no. 8, pp. 705-740, 2004.

[7] K. Y. Dai, G. R. Liu, X. Han, and K. M. Lim, "Thermomechanical analysis of functionally graded material (FGM) plates using element-free Galerkin method," Computers and Structures, vol. 83, no. 17-18, pp. 1487-1502, 2005.

[8] A. J. M. Ferreira, R. C. Batra, C. M. C. Roque, L. F. Qian, and P. A. L. S. Martins, "Static analysis of functionally graded plates using third-order shear deformation theory and a meshless method," Composite Structures, vol. 69, no. 4, pp. 449-457, 2005.

[9] S. H. Chi and Y. L. Chung, "Mechanical behavior of functionally graded material plates under transverse load-Part I: analysis," International Journal of Solids and Structures, vol. 43, no. 13, pp. 3657-3674, 2006.

[10] S.-H. Chi and Y.-L. Chung, "Mechanical behavior of functionally graded material plates under transverse load-part II: numerical results," International Journal of Solids and Structures, vol. 43, no. 13, pp. 3675-3691, 2006.

[11] H. Wang and Q.-H. Qin, "Meshless approach for thermomechanical analysis of functionally graded materials," Engineering Analysis with Boundary Elements, vol. 32, no. 9, pp. 704-712, 2008.

[12] M. Mahdavian, "Buckling analysis of simply-supported functionally graded rectangular plates under non-uniform in-plane compressive loading," Journal of Solid Mechanics, vol. 1, no. 3, pp. 213-225, 2009. 
[13] M. Z. Ashraf and S. M. Daoud, "Thermal buckling analysis of ceramic-metal functionally graded plates," Natural Science, vol. 2, no. 9, pp. 968-978, 2010.

[14] S. S. Alieldin, A. E. Alshorbagy, and M. Shaat, "A first-order shear deformation finite element model for elastostatic analysis of laminated composite plates and the equivalent functionally graded plates," Ain Shams Engineering Journal, vol. 2, no. 1, pp. 53-62, 2011.

[15] N. Kyung-Su and K. Ji-Hwan, "Comprehensive studies on mechanical stress analysis of functionally graded plates," World Academy of Science, Engineering and Technology, vol. 60, pp. 768-773, 2011.

[16] K. Suresh, S. R. Jyothula, E. R. C. Bathini, and K. R. K. Vijaya, "Nonlinear thermal analysis of functionally graded plates using higher order theory," Innovative Systems Design and Engineering, vol. 2, no. 5, pp. 1-13, 2011.

[17] T. Mohammad and B. N. Singh, "Thermo-mechanical deformation behavior of functionally graded rectangular plates subjected to various boundary conditions and loadings," International Journal of Aerospace and Mechanical Engineering, vol. 6, no. 1, pp. 14-25, 2012.

[18] H. Nguyen-Xuan, L. V. Tran, C. H. Thai, and T. Nguyen-Thoi, "Analysis of functionally graded plates by an efficient finite element method with node-based strain smoothing," ThinWalled Structures, vol. 54, pp. 1-18, 2012.

[19] E. Alshorbagy, S. S. Alieldin, M. Shaat, and F. F. Mahmoud, "Finite element analysis of the deformation of functionally graded plates under thermomechanical loads," Mathematical Problems in Engineering, vol. 2013, Article ID 569781, 14 pages, 2013.

[20] M. Bhandari and K. Purohit, "Analysis of functionally graded material plate under transverse load for various boundary conditions," IOSR Journal of Mechanical and Civil Engineering, vol. 10, no. 5, pp. 46-55, 2014.

[21] M. Bhandari and K. Purohit, "Static response of functionally graded material plate under transverse load for varying aspect ratio," International Journal of Metals, vol. 2014, Article ID 980563, 11 pages, 2014. 

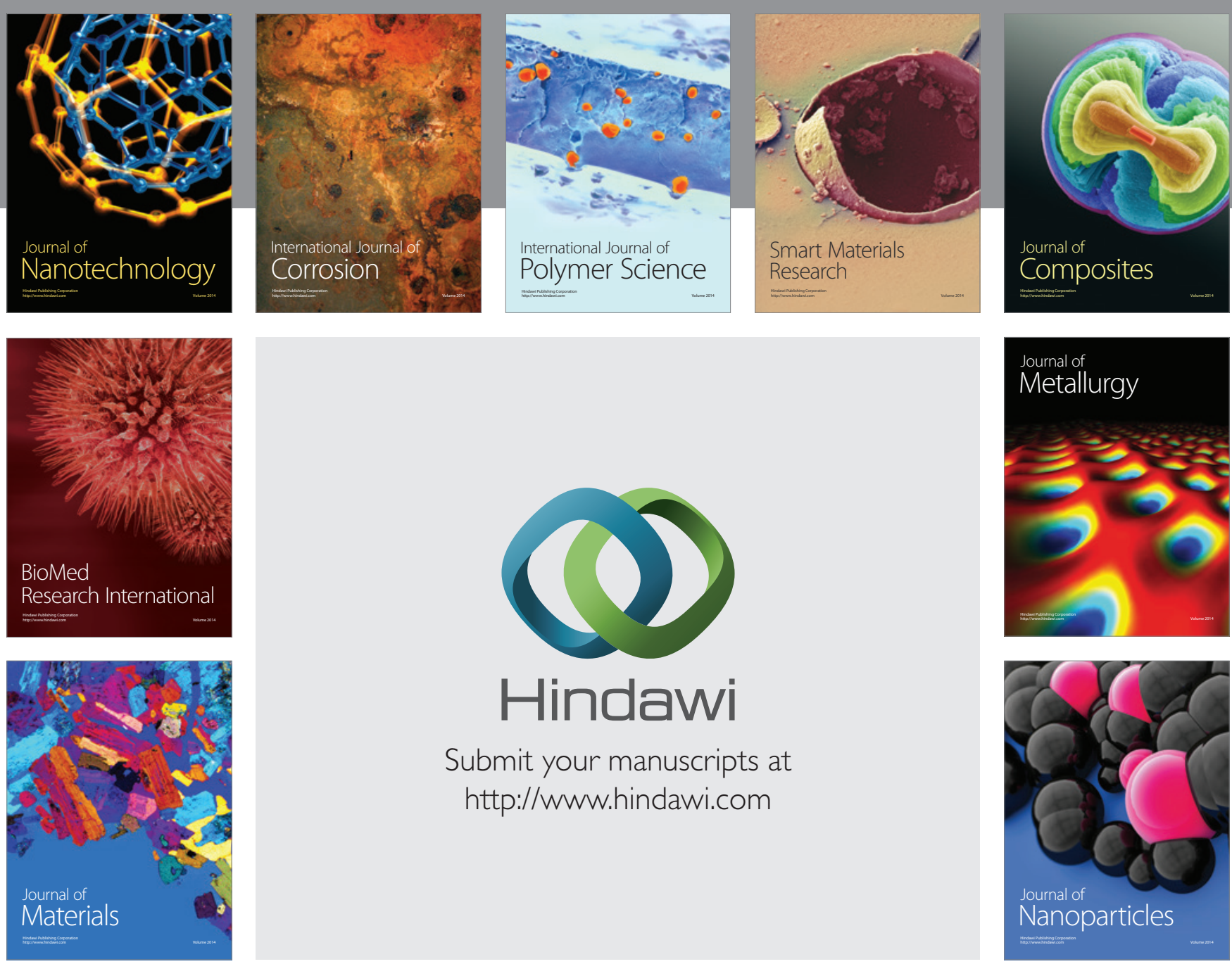

Submit your manuscripts at http://www.hindawi.com
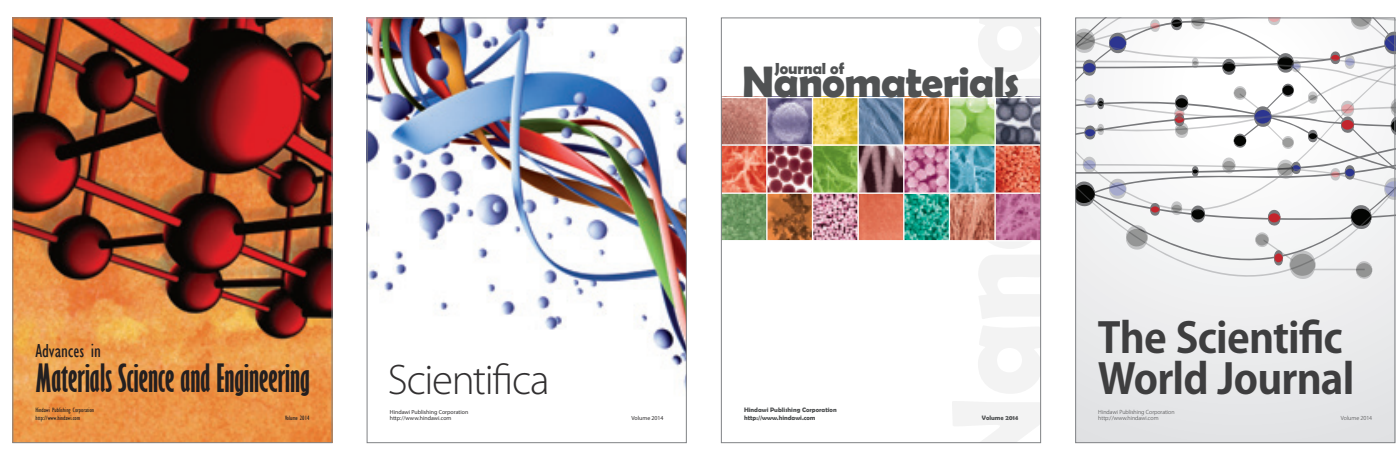

\section{The Scientific World Journal}
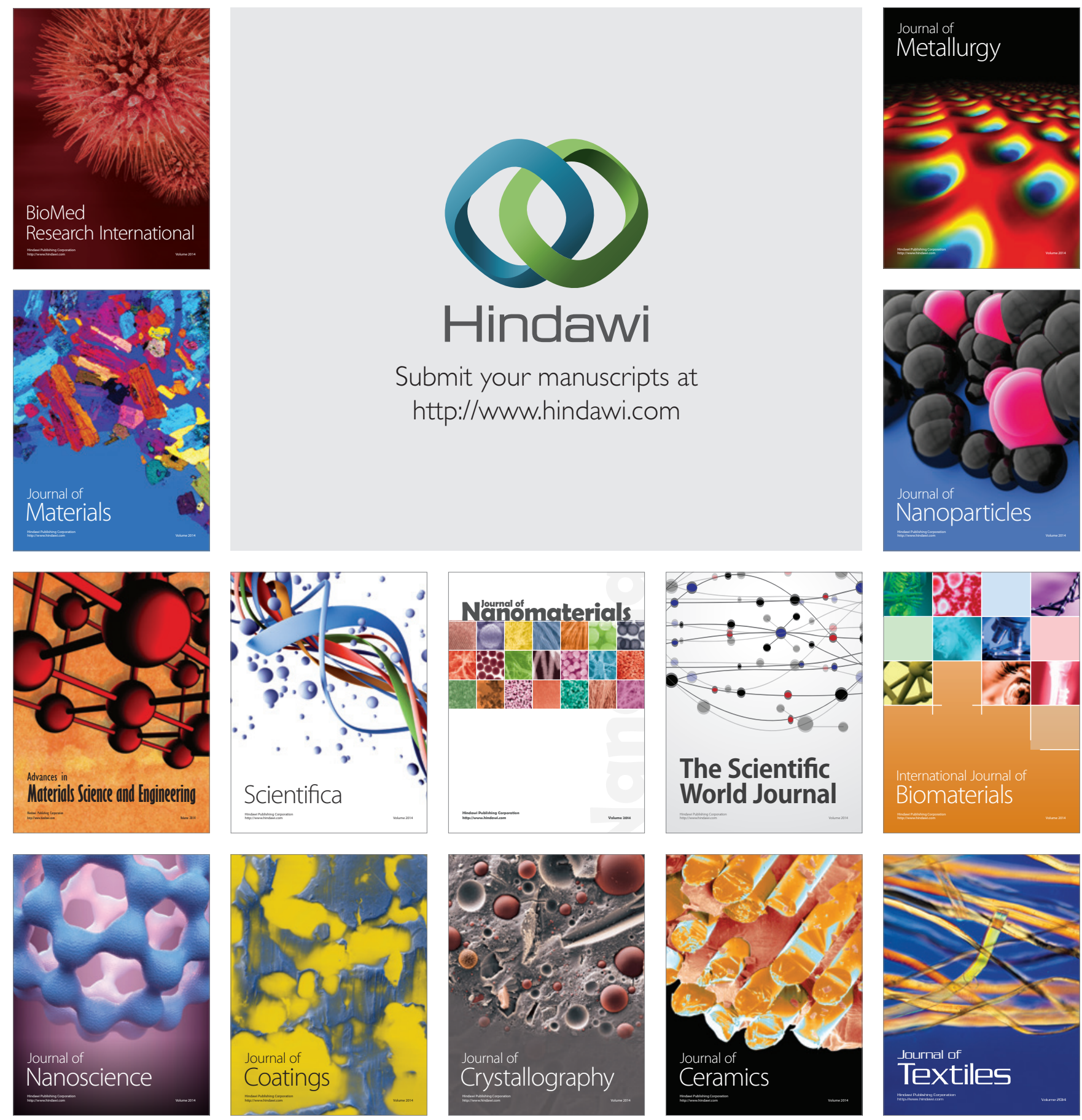